C2019, Elsevier. This manuscript version is made available under the CC-BY-NC-ND 4.0 license http:// creativecommons.org/licenses/by-nc-nd/4.0/

\title{
Dynamics of flow transitions from bubbly to churn flow in high viscosity oils and large diameter columns
}

\author{
Shara K. Mohammed ${ }^{a, b, *}$, Abbas H. Hasan ${ }^{c}$, Abubakr Ibrahim ${ }^{a}$, Georgios Dimitrakis ${ }^{a}$, Barry
}

\section{J. Azzopardia}

\author{
a. Faculty of Engineering, University of Nottingham, Nottingham NG72RD, United Kingdom \\ b. Department of Petroleum Technology, Erbil Polytechnic University, Erbil, Kurdistan region-Iraq \\ c. Faculty of Engineering, University of Hull, Hull HU6 7RX, United Kingdom
}

\begin{abstract}
The dynamic behaviour of the gas-liquid two phase flows and in particular the flow pattern stability and transition between the flow regimes are influenced significantly by both the properties of the liquid and gas as well as the pipe diameter. The majority of the studies reported in the literature on the dynamics of gas-liquid flow transitions focus only on low viscosity liquids (e.g. water) and small diameter pipes. In the present work a series of experiments were carried out to study the dynamics of flow transitions (bubbly to slug and slug to churn) of gas rising through very viscous oils (330 Pa.s and 360 Pa.s) in two large diameter columns (290 and $240 \mathrm{~mm}$ respectively), using Electrical Capacitance Tomography (ECT) and pressure sensors. The experiments aimed to imitate a number of realistic flow conditions that might be encountered, for examples, in; bitumen, crude oil, viscous liquids in food processing and volcanic magmatic flows. Observation and quantification of bubbly to slug and slug to churn flow transitions for gas-high viscous liquids in large pipe diameters are presented for the first time. Flow parameters and characteristics including; void fraction, pressure gradient, Probability Density Function, structure velocity, lengths of large/Taylor bubbles and liquid slugs and the effect of liquid temperature on the void fraction and Taylor bubble lengths, were measured and analysed. It was found that transition to slug and churn flow occurs gradually. Transition to slug flow occurs at a gas superficial velocity of $0.011 \mathrm{~m} / \mathrm{s}$ to $0.016 \mathrm{~m} / \mathrm{s}$, while transition to churn appears in the range of 0.127 to $0.243 \mathrm{~m} / \mathrm{s}$ in both columns.
\end{abstract}

\section{Keywords:}

High viscosity liquids, flow transitions, large diameter, Taylor bubbles, churn flow, Electrical Capacitance Tomography

\section{Introduction}


High viscosity liquids are ubiquitous in many industrial applications, for instance in crude oil and bitumen production (up to 2000 Pa.s), Shu (1984), polymer manufacturing (100-1000 Pa.s), and food processing. It is also relevant for understanding the dynamics of some natural phenomena, one of which is the prediction of the volcanic degassing process where gas-Silicatic magmas, with a viscosity commonly ranging between 100-1000 Pa.s ,rise in volcanic conduits as multiphase mixtures. Understanding the physical characteristics that underpin the behaviour of these viscous fluids is important for designing industrial units as well as assessing environmental impacts of volcanic activity.

Pioli et al. (2012) studied flow of magmatic fluids $(6.5,200,280$, and $300 \mathrm{~Pa}$ s) in a large vertical conduit using a mixture of glucose syrup and water. The study revealed that the average void fraction (in volcanography referred to as vesicularity) increases with increasing gas superficial velocity and liquid viscosity. Looking at the effect of the conduit diameter on the flow, void fraction was found to decrease with increasing diameter. Pressure gradient was observed to decrease with increasing liquid viscosity and decreasing diameter.

Kajero et al. (2018) investigated the effect of viscosity in a small diameter $(0.05 \mathrm{~m})$ bubble column dynamics covering viscosities in the range of 0.005 to $5 \mathrm{~Pa}$. They observed a tendency of extended prevalence of slug flow with increasing liquid viscosity. They also observed a decrease of liquid void fraction in both liquid slugs and Taylor bubbles with increasing liquid viscosity. Sharaf et al. (2017) studied the effect of viscosity on the bubble dynamics in a quiescent liquid of viscosities up to $1.7 \mathrm{~Pa}$. The study revealed that bubble dynamics are highly dependent on both density and viscosity ratios and their conclusions were confirmed both numerically and experimentally.

Ruzicka et al. (2003) studied the influence of viscosity on bubble column behaviour at much lower viscosities $(<0.022$ $\mathrm{Pa} \mathrm{s}$ ), the study revealed that the increase of viscosity shifts the flow regime in the bubbly flow region more into the nonhomogeneous flow by promoting bubble coalescence.

The study of Bousman et al. (1996) reported that the bubble-slug regime transition is affected by the physical properties of the liquid (viscosity and surface tension) suggesting that the transition is highly dominated by bubble-induced turbulence. On the other hand, the churn-annular transition was minimally affected by the change in physical properties. Wilkinson et al. (1993) reported that increasing liquid viscosity hinders bubble coalescence, which suggests that overall void fraction is likely to increase with increasing liquid viscosity. Philip et al. (1990) studied bubble flow in a viscous loop reactor, investigating viscosities up to $3 \mathrm{~Pa}$.

\section{Transition of flow regimes}

It is evident that gas-liquid flows are highly dependent on both the physical properties and geometrical aspects of the conduit (Azzopardi (2006), Brennen and Brennen (2005), Crowe (2005), Shen et al. (2014)). The Transition of flow regimes is therefore expected to be influenced by these attributes. Since two-phase flow behaviour is highly complex and 
non-linear, scaling proves to be a real challenge. Models and mechanisms proposed for certain smaller geometries would likely deviate dramatically for lager geometries and different physical properties. It would be interesting to study how regime transition mechanisms, which are mostly generated for air-water systems in small diameter pipes, would translate at very high viscosity and in a large diameter pipe.

\section{Bubbly-slug transition}

The transition from bubbly flow to slug flow is dependent on the competition between bubble coalescence and break-up, where transition occurs when coalescence dominates and bubbles eventually grow to form Taylor bubbles. A bubble would only become a slug flow Taylor bubble if its equivalent diameter grows larger than that of the pipe (Taitel et al., 1980). This would entail that transition is directly influenced by the pipe diameter. On the other side, liquid viscosity directly affects bubble rise velocity due to drag, transverse movement of bubbles, and bubble-induced turbulence; factors that greatly impact on coalescence and break-up of bubbles that govern bubble-slug transition.

Taitel et al. (1980) suggested that transition to Slug flow happens when void fraction reaches 0.2-0.3. Which corresponds to the maximum number of bubbles that can fit in a cube without significant increase in their coalescence rate. While Radovcich and Moissis (1962) proposed a model to predict transition to slug flow based on probability of successful bubble coalescence as a function of pipe diameter, void fraction and velocities, however it does not consider the physical properties of the fluids

\section{Slug-churn transition}

Churn flow is characterised by a froth of small bubbles and cap-sized bubbles with large unstable incoherent structure of bubbles that coalesce and break-up very frequently. The most distinctive feature of churn flow is the intermittent downward movement of the liquid film as large gas structures rise up the vertical column. For more comprehensive study on churn flow especially at high viscosities and in large diameter pipes attention is drawn to the work of Mohammed et al. (2018). One of the popular transition mechanisms is that proposed by Mishima and Ishii (1984) and Chen and Brill (1997), where transition is thought to occur when Taylor bubbles grow long enough so the wake of the leading bubble touches the nose of the following bubble causing the slug to collapse creating large liquid structures. This condition is postulated to occur when the average void fraction in the liquid slug is larger than or equal to that of the Taylor bubble section. This mechanism is usually referred to as the wake effect mechanism. Nicklin et al. (1962) proposed a mechanism, which relates transition to flooding of the liquid film enveloping the Taylor bubble. Hewitt and Hall-Taylor (1970) proposed a detailed experimental approach to determining transition point. 
A number of investigators, like Taitel et al. (1980), suggested that churn flow is a developing flow regime for slug flow, that was based on the back flow of the liquid slug as two unstable Taylor bubbles coalesce as slugs develop. Brauner and Barnea (1986) proposed a different mechanism based on the bubbles coalescence.

\section{Churn-Annular transition}

Transition to annular flow starts when a continuous gas core is formed where the liquid mostly travel as waves and film on the pipe wall. Full transition occurs when the gas superficial velocity is high enough to carry the largest stable droplet in the gas core upwards. Hinze (1955) proposed a transition mechanism based on drag and gravity forces balance around a stable droplet in the gas core.

Only a few authors have reported studies on the dynamics of gas-very viscous liquid flows (>1 Pa s) and even fewer have shed light on the nature of regime transitions and elaborated on the potential associated transition mechanisms . The aim of the present study is to investigate the characteristics of gas passage through columns of very viscous liquids by focusing on the hydrodynamics of the transitions between flow regimes. This papers reports experimental results obtained using quiescent Silicon oils of 360 and 330 Pa.s in columns of 240 and $290 \mathrm{~mm}$ diameter respectively. Electrical Capacitance Tomography (ECT) was employed to collect information about the characteristics of two-phase flow in both columns. Mean void fraction, Probability Density Function (PDF), structure velocity, film thickness, pressure gradient, large bubbles and liquid slugs lengths, effect of temperature, frequency and top surface oscillation were all determined and compared with analytical approaches from literature.

\section{Experimental setup}

In the present work, two similar experimental settings with different diameter columns were used to study the characteristics of gas-high viscosity liquids in large diameter columns (open to the atmosphere). The 240 and $290 \mathrm{~mm}$ internal diameter columns contained Silicone oils with a viscosity of 360 and 330 Pa.s respectively. A dual-plane Electrical Capacitance Tomography, ECT sensor is placed at $2.56 \mathrm{~m}$ from the gas inlet points in both columns, see Figure 1. The ECT sensor is connected to a TFLR 5000 electronic box and a PC for data acquisition and processing. This nonintrusive sensor measures the cross section distribution of capacitance in the column, which can then be correlated to the cross section phase distribution for the non-conductive liquids. The sensor is capable of measuring up to 5000 frames per seconds with excitation frequency range of 1 to $10 \mathrm{MHz}$. Electrical Capacitance Tomography is one of the common nonintrusive techniques used to reconstruct the internal structure of the pipe flow. The validation of the ECT was achieved, by comparing the results with those generated by Wire Mesh Sensor, WMS (Azzopardi et al., 2010). Detailed information on the ECT techniques can be found elsewhere, Abdulkareem (2011). ECT technique was also validated by Pradeep et 
al. (2014) and Marashdeh (2009). Air superficial velocities of 0.005-0.314 and 0.003-0.566 m/s were injected into the 240 and $290 \mathrm{~mm}$ diameter columns respectively. In each run, data was measured for $600 \mathrm{~s}$ with a sampling rate of $50 \mathrm{~Hz}$. Figure 1 displays the experimental apparatus used in the present work showing the gas injection arrangement, instrumentation, and the dimensions. The apparatus is also equipped with a number of thermocouples to measure the temperature of the air at the gas lines besides the air-oil mixture in the column. Both columns contain stagnant Silicone oil with initial heights of $3.30 \mathrm{~m}$, see the properties of the fluids in Table 1 . The gas injection system consists of two main gas lines in order to obtain a wide range of gas flow rates, high pressure line of 6 bar and low pressure line of 2 bar. The high-pressure line is connected to five flow meters and pressure gauges. Then each line is divided into five more lines. Thus, the total number of the gas injection lines is 25 lines distributed equally at the bottom of the column. Sealed pressure transmitters (Keller, PR-25/8797.1-5) were mounted along the $290 \mathrm{~mm}$ diameter column to read a continuous pressure outputs. The pressure transmitters are installed at 2.2 and $3.6 \mathrm{~m}$ from the gas inlet section. The pressure measurements were recorded at a sampling rate of $50 \mathrm{~Hz}$ for $300 \mathrm{sec}$ at flow rate range of 10-3000 L/min (Mohammed et al., 2018)

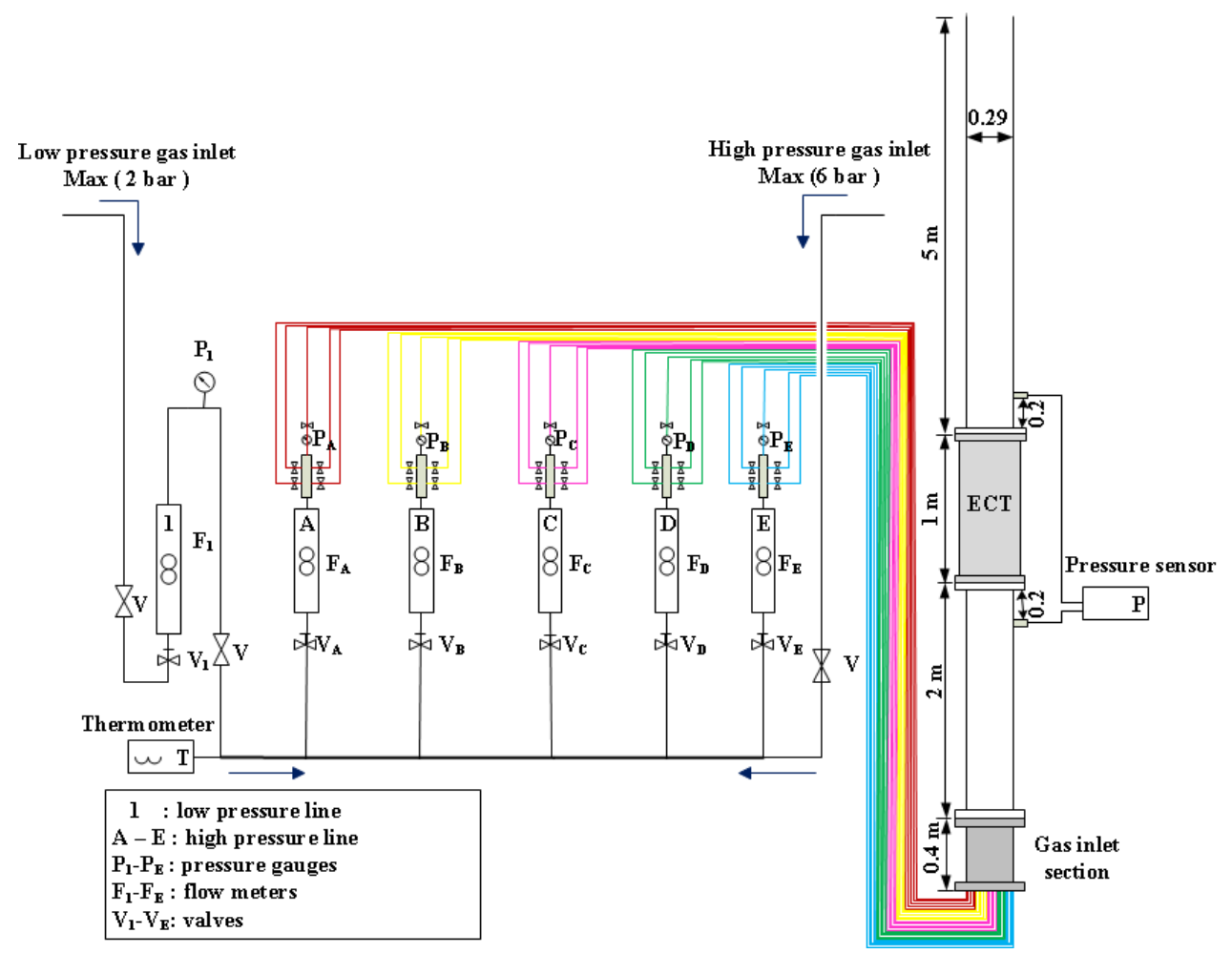

Figure 1: Experimental setup used in the present study 
Table 1: Properties of the fluids employed in the current study

\begin{tabular}{|c|c|c|c|c|c|}
\hline \multicolumn{6}{|c|}{ Silicone oil } \\
\hline $\begin{array}{l}\text { Column diameter } \\
\qquad \mathrm{m}\end{array}$ & $\begin{array}{c}\text { Viscosity } \\
\text { Pa.s }\end{array}$ & $\begin{array}{l}\text { Density } \\
\mathrm{Kg} / \mathrm{m} 3\end{array}$ & $\begin{array}{c}\text { Surface } \\
\text { tension } \\
\mathrm{N} / \mathrm{m}\end{array}$ & 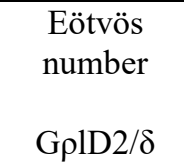 & $\begin{array}{l}\text { Buoyancy } \\
\text { Reynold } \\
\text { number }\end{array}$ \\
\hline 0.24 & 360 & 950 & 0.02 & 26812 & 0.97 \\
\hline 0.29 & 330 & 950 & 0.02 & 39148 & 1.4 \\
\hline \multicolumn{6}{|c|}{ Air } \\
\hline $\begin{array}{c}\text { Column diameter } \\
\text { m }\end{array}$ & $\begin{array}{c}\text { Gas injections } \\
\text { diameters } \\
\text { mm }\end{array}$ & $\begin{array}{l}\text { Density } \\
\text { Kg/m3 }\end{array}$ & $\begin{array}{c}\text { Low- } \\
\text { pressure gas } \\
\text { line } \\
\text { bar }\end{array}$ & $\begin{array}{c}\text { High- } \\
\text { pressure gas } \\
\text { line } \\
\text { bar }\end{array}$ & $\begin{array}{c}\text { Temperature } \\
{ }^{\circ} \mathrm{C}\end{array}$ \\
\hline 0.24 & 3 & 1.225 & 2 & 6 & $20-23$ \\
\hline 0.29 & 4 & 1.225 & 2 & 6 & $19-22.5$ \\
\hline
\end{tabular}

\section{Results}

\subsection{The characteristics of air flow in viscous liquids}

As has been previously mentioned, flow of air in high viscosity liquids features significantly different characteristics compared with water and lower viscosity liquids which are most commonly employed in gas-liquid studies. In these sets of experiments, a wide range of air flow rates were employed to assess and build a full picture of the hydrodynamic characteristics of flow and cover a variety of flow regimes.

In this paper, the various attributes of two-phase flow characteristics are presented with reference to the occurring flow regime. This flow regime characterisation was determined using a combinatorial approach. The assessment included visual observation of the flow in the lab while running the experiment, studying the time-series of cross-sectionally averaged void fraction, videos of the flow, along with observing videos of the ECT tomographs. In some figures of this section, $\mathrm{x}$-axis is presented in a logarithmic scale, mostly for the gas superficial velocity, to highlight behaviour at low velocities that would otherwise be stacked if represented in a linear scale.

\subsubsection{Visual Observation and Image Reconstruction}

Visual methods, which are the simplest approach to observe the flow structure through the transparent walls of the column, were the first step applied in collecting information. In general, in gas-viscous liquid flows, the gas flows mainly in large 
bubbles (spherical and Taylor bubble) which occupy almost the entire cross-sectional area for the majority of the gas flow rates. These large bubbles are accompanied by small bubbles, which range in size from very small bubbles of millimetres to large ones of centimetres size.

The large bubbles, which can be seen in Figure 2, dominate the flow structure in both the viscous oils studied. They rise in the centre of the column due to the wall shear effect. The shape of these bubbles is mainly dependent on the gas flow rate. At low gas superficial velocities lbubbly flow $(0.003 \mathrm{~m} / \mathrm{s}$ in Figure 2$)$ the bubble rises at a constant velocity and size. The bubbles are spherical due to the surface tension of the oil which has a significant effect only in low gas flow rates (Wraith, 1971, Feng, 2008). In addition, no bubble coalescence was observed at this flow pattern. The bubble is followed by a wake containing a small number of small bubbles that rise in rectilinear trajectories and increase in density with increasing the gas flow rate. The rate of increase of these small bubbles appeared to be not only dependent on the gas flow rate, but also on the time over which gas was injected into the column, Mohammed (2017).

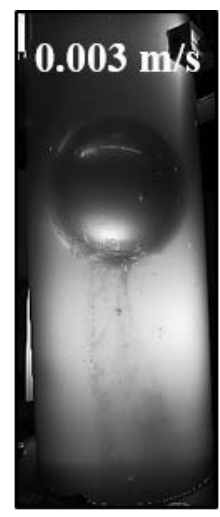

Bubbly

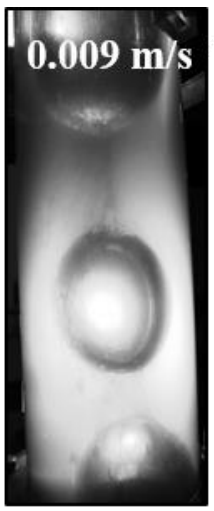

Transition to slug flow

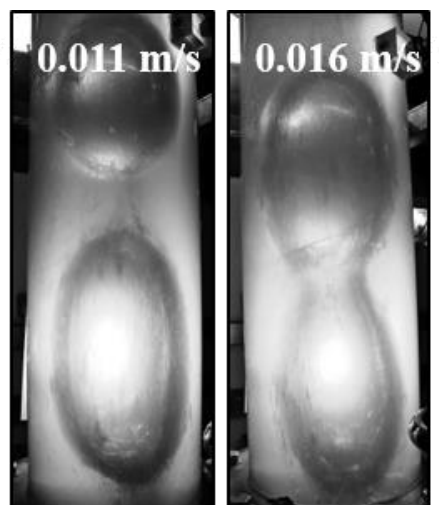

\begin{abstract}
(n)
\end{abstract}
.

Figure 2: Photographic images show bubbly to slug flow patterns in 330 Pa.s Silicone oil and 290 mm diameter column.

At the transition to slug flow $0.009,0.011,0.016 \mathrm{~m} / \mathrm{s}$ gas superficial velocities in Figure 2, the large bubbles vary in size i.e. two different types of large bubbles appear. One is spherical and similar to bubbly flow regime and the second is ellipsoidal with slightly larger diameter due to shear force. With increasing gas flow rate the effect of surface tension is ceases to be significant (Feng, 2008). The velocity of the bubbles vary due to the difference in bubble size. Larger bubble rises faster because of the balance between the buoyant weight and the drag force, Feng (2008), Dumitrescu (1943), Gibson (1913). This enhances bubble coalescence in this flow pattern. The larger trailing bubble rises faster to eventually catch up and coalesce with the slower leading bubble creating larger bubbles similar to Taylor bubbles. However, these bubbles are quite distinct because they have a rounded tip and tail altogether, featuring a symmetrical oval body. Traditional Taylor bubbles have a flat end where the downward falling film around the bubble meets the upward moving liquid slug, generating a lot of turbulent vortices in the wake, distorting the interface to the dynamic flat shape observed. 
To understand better the physics underpinning the behaviour of rounded tail Taylor bubbles , the movement of small bubbles trapped in the liquid film/bulk was observed. Their trajectories suggest that, in concordance with the behaviour in lower viscosities, the liquid film around the Taylor bubble moves downwards. However, when it meets the upwards travelling slug at the tail of the bubble, no turbulent mixing is observed. The bubbles in the film change direction following a turning trajectory featuring approximately a semi-circular shape as described in Figure 3. This potentially indicates that, due to the very high viscosity, and subsequently low Reynolds number, the turbulence in the wake is significantly dampened. As a result, not many vortices were observed in the wake, therefore the interface remains smooth and undisturbed. A similar shape bubbles were numerically predicted for micro and millimetre channel flow in the study of Rocha et al. (2017), where the rear of the bubbles was reported to become more concave with increasing the Capillary and Reynolds number. The high viscosity in this study is consistent with the increase in Capillary number, though not the Reynolds. Viana et al. (2003) and Llewellin et al. (2012) reported similar shape bubbles in still liquids with varying viscosities, the bubbles' rear was observed to become rounder and more uniform with increasing viscosity (low Reynolds number).

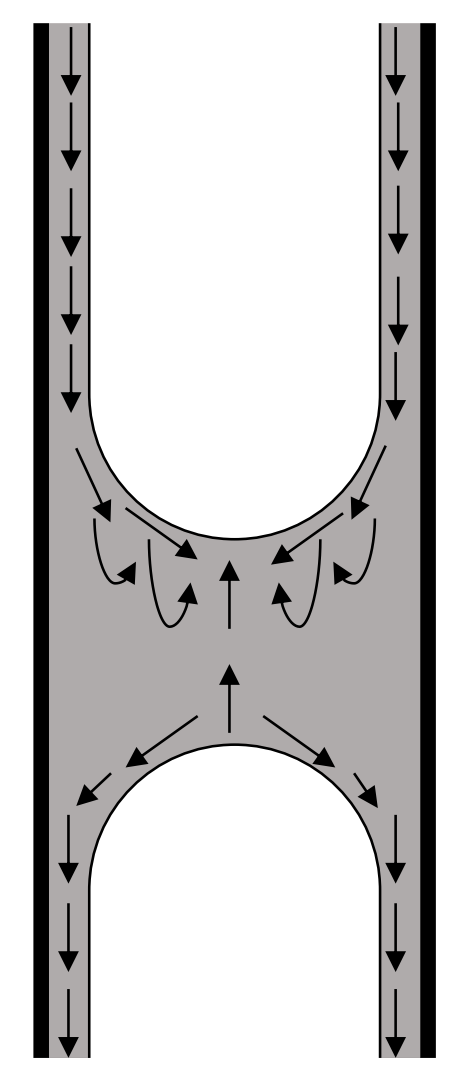

Figure 3: A representation of flow trajectories of small bubbles surrounding the rounded tip and tail Taylor bubbles 
observed in gas-viscous liquid flow in large diameter pipes.

Further increase in the gas flow rate produces long cylindrical bubbles with rounded top and end (Taylor bubble). This is the point where slug flow starts; see $0.023 \mathrm{~m} / \mathrm{s}$ in Figure 2 . Increasing the flow rate at this stage increases bubble coalescence, which is in turn, increases the length of Taylor bubbles, see $0.088 \mathrm{~m} / \mathrm{s}$ in Figure 2.

The structure of the flow changes significantly as the flow pattern goes from slug to churn. It starts from the flooding of the falling film around Taylor bubbles as liquid bridges, $0.108-0.243 \mathrm{~m} / \mathrm{s}$ in Figure 4 . Then at the very high flow rate, where the churn flow starts, the air flows in a random shape conduit in the column of viscous liquids, 0.336 and 0.566 $\mathrm{m} / \mathrm{s}$ in Figure 4. The characteristics of the flow in these two flow regimes were studied in detail by Mohammed et al. (2018).

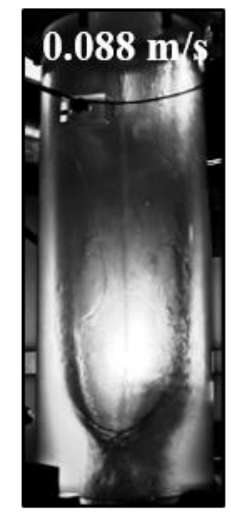

Slug

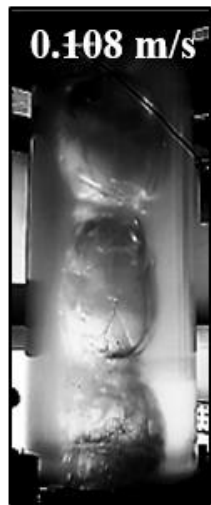

Transition to churn flow

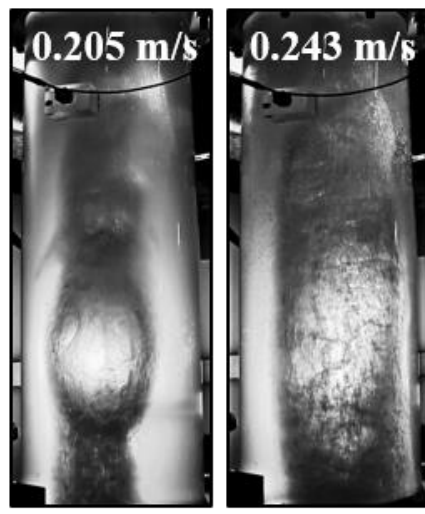

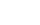

Figure 4: Photographic images show slug to churn flow patterns in 330 Pa.s Silicone oil and 290 mm diameter column.

Figure 5 shows the structure of the flow at the start $(0.108 \mathrm{~m} / \mathrm{s})$ and the end $(0.243 \mathrm{~m} / \mathrm{s})$ of transition to churn flow regime. Transition to churn flow starts when the frequency of the liquid bridges, which is created from the drained falling film around the long Taylor bubbles, increases. Long Taylor bubbles lose their structure and deform creating an open core accompanied by liquid bridges. This flow regime has complex structures that do not maintain a uniform pattern even at a constant flow rate. 


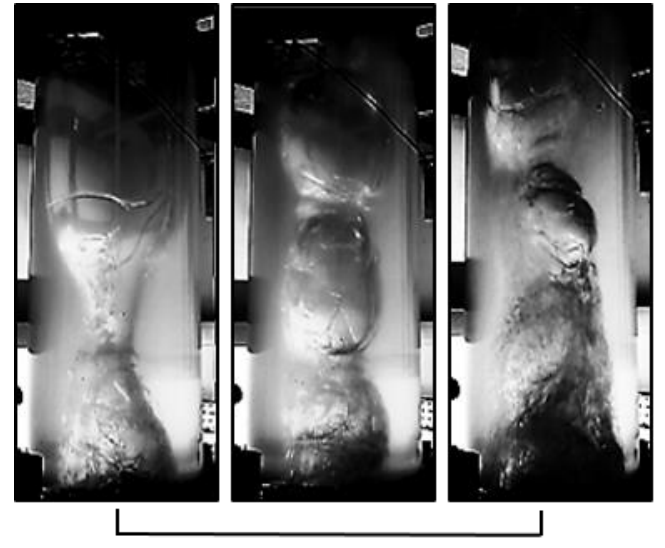

$(0.108 \mathrm{~m} / \mathrm{s})$

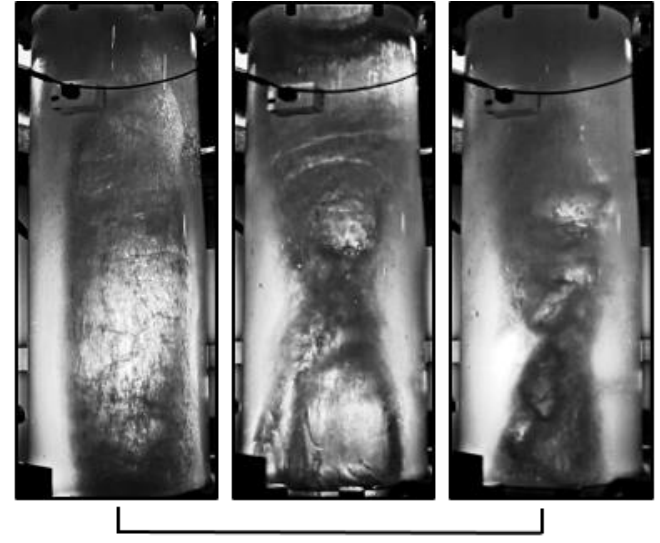

$(0.243 \mathrm{~m} / \mathrm{s})$

Figure 5: Photographic images show transition to churn flow regime at two different gas superficial velocities in 330 Pa.s Silicone oil and $290 \mathrm{~mm}$ diameter column.

Figure 6 shows a schematic drawing for the flow patterns for high viscosity liquids in vertical large diameter pipes. It displays the structure of gas flow in 330 Pa.s Silicone oil and $290 \mathrm{~mm}$ diameter column. The original photos for the corresponding gas superficial velocities in this figure are displayed in Figure 2 and Figure 4. Schematic drawings for the overall flow structure in viscous liquids for all flow regimes is presented by Mohammed (2017).

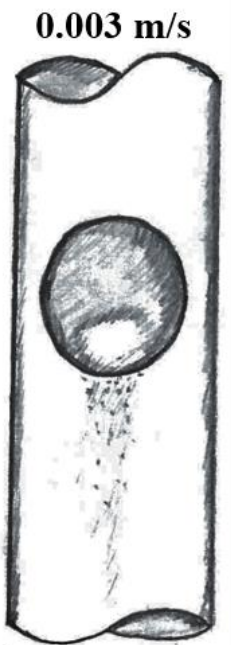

Bubbly

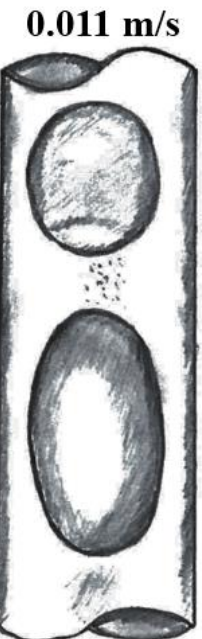

Transition to slug

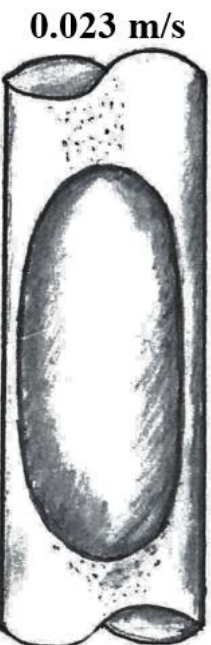

Slug

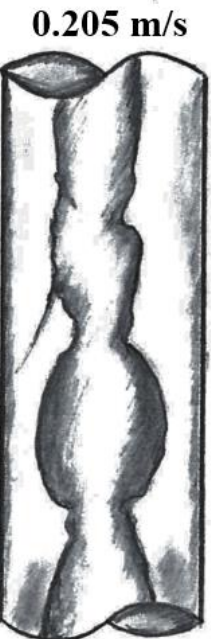

Transition to churn

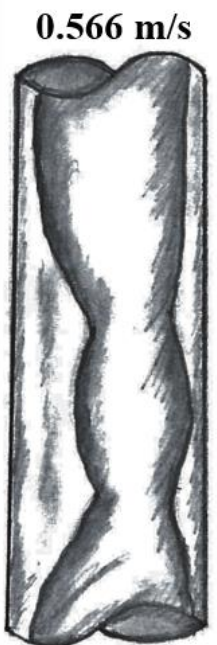

Churn

Figure 6: Schematic drawing showing the flow patterns in 330 Pa.s Silicone oil and $290 \mathrm{~mm}$ diameter vertical pipe. The arrows in the figure correspond to the direction of the liquid flow. The flow patterns in the figure correspond to the photos in Figure 2 and Figure 4.

In addition to large bubbles in gas-viscous liquids flow a significant number of the small bubbles is also observed. They are generated mainly from bubbles' eruption at the top of the liquid in the column (Bird et al. (2010), Pandit et al. (1987)). 
They are also formed at the gas injection nozzles at the bottom of the column, and also from the coalescence of bubbles while rising in the column, Otake et al. (1977) and Pandit et al. (1987). The diameter of these bubbles varies between few millimetres to a few centimetres. Similar mechanism of the small bubble generation was reported by Pioli et al. (2012) and Azzopardi et al. (2014).

Figure 7 shows the single axial slices for 10000 frames for different gas flow rates. The images are a reconstruction of void fraction distribution for air-Silicone oil 330 Pa.s viscosity in the $290 \mathrm{~mm}$ columns. These 2D slices display 10000 frames of cross-sectional void fraction measurements for the gas-liquid flow in the column. The blue represents the gas phase whilst the red indicated the liquid phase. The axial dimension (y-axis) of these images is not a true representation of the phase evolution along the length of the pipe, as it is an arbitrary scale representing pixels obtained from different cross-sectional frames. The photos in Figure 2 and Figure 4 show an agreement with the axial slices from the ECT in Figure 7 for the selected range of gas superficial velocities. A more quantitative method for assessing flow regime transitions can be found in the time series of void fraction and PDF in section 3.1.2.

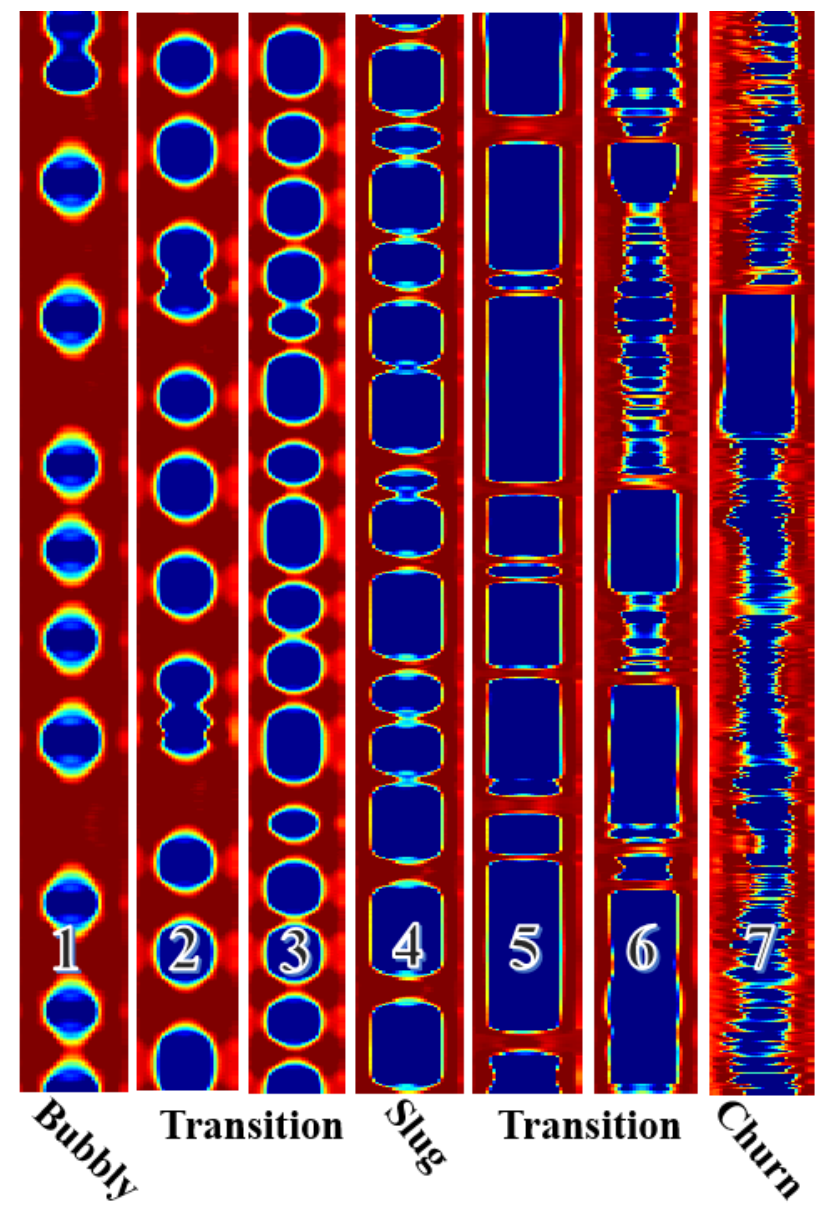

Figure 7: Reconstructed images of the gas flow in viscous Silicone oil for different gas superficial velocities in $290 \mathrm{~mm}$ 
diameter column. Blue, red and Green colours represent air, Silicone oil and the mixed area between both fluids respectively. The images are sets of multiple two-dimensional image frames as 2D slices (10000 frames). Column (1) is at gas superficial velocity of $0.003,(2)$ is $0.009,(3)$ is $0.016,(4)$ is $0.023,(5)$ is $0.108,(6)$ is 0.205 and $(7)$ is $0.566 \mathrm{~m} / \mathrm{s}$.

\subsubsection{Time Series of Cross-Sectional Averaged Void Fraction}

The time series of the cross-sectionally averaged void fraction can be used to study the characteristics of the flow structure for different flow patterns. The information about phase distribution in this section was obtained using the ECT, which provides time and cross-section resolved information. Figure 8 and Figure 9 show the time series plots of void fraction for a wide range of gas superficial velocity in both columns.

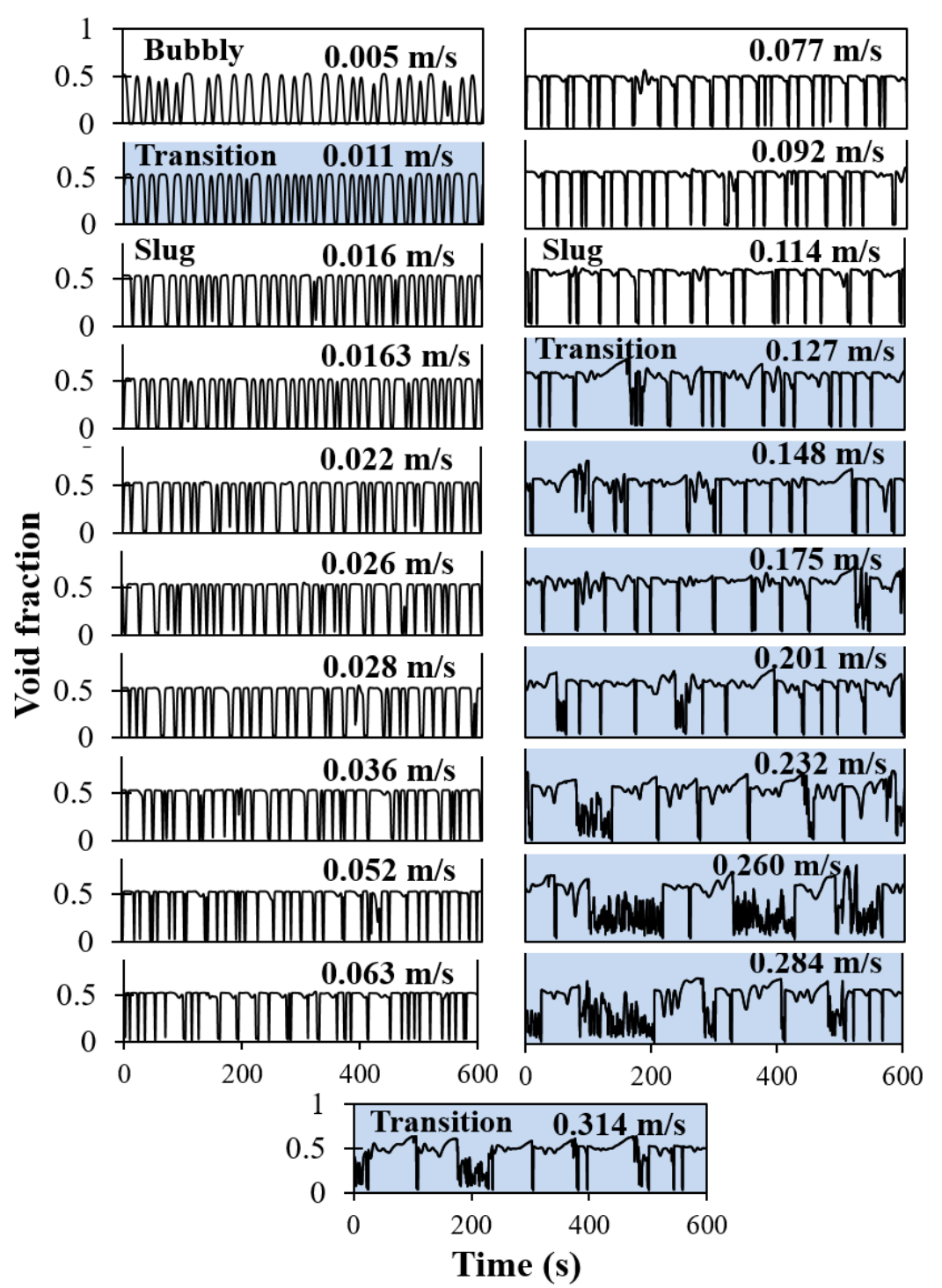

Figure 8: Time series of the cross-sectional averaged void fraction showing the transitions between the flow patterns in 
360 Pa.s Silicone oil $240 \mathrm{~mm}$ diameter column. The shaded graphs represent the transitions between the flow regimes.

Both Figure 8 and Figure 9 show the transition between two flow regimes in 240 and $290 \mathrm{~mm}$ diameter columns. Bubbly flow appears at $0.005 \mathrm{~m} / \mathrm{s}$ gas superficial velocity in the smaller diameter column while it appears at $0.003 \mathrm{~m} / \mathrm{s}$ in the $290 \mathrm{~mm}$ diameter column $(0.005 \mathrm{~m} / \mathrm{s}$ in both columns). It starts with small bubbles with low void fraction and low frequency. The liquid slug lengths in this stage are higher than the bubbles. There is no widespread evidence of bubble coalescence. Transition starts when the bubbles become larger, resulting to a larger void fraction and bubble frequency Transition to slug flow occurs at $0.011 \mathrm{~m} / \mathrm{s}$ and between $0.009-0.016 \mathrm{~m} / \mathrm{s}$ in 240 and $290 \mathrm{~mm}$ diameter columns respectively $(0.011 \mathrm{~m} / \mathrm{s}$ in both columns).

Further increase in gas superficial velocities, where slug flow appears, the flow becomes less structured especially in the last two graphs in this range. The bubbles become longer and the coalescence increases with increasing the gas flow rate. The slug flow seemed to occur for a wider range in the smaller column, $0.016-0.114 \mathrm{~m} / \mathrm{s}$, while it only appeared in the range $0.023-0.088 \mathrm{~m} / \mathrm{s}$ in the larger diameter one. Slug flow occurred between 0.023 to $0.088 \mathrm{~m} / \mathrm{s}$ in both columns.

The structure of the flow is changing totally at the transition to churn flow regime. It consists of very long bubbles with high void fraction separated by low void fraction churning regions. The churning regions consist of liquid bridges which create from the accumulation of the falling film around the large bubbles. The churn regions start to appear at the beginning of the transition to churn regime and become more frequent and longer with increasing flow rate. The transition to churn flow was longer in the smaller column $0.127-0.314 \mathrm{~m} / \mathrm{s}$ in Figure 8. However, in the larger diameter column, churn flow recorded with shorter transition region $0.108-0.243 \mathrm{~m} / \mathrm{s}$. Therefore, transition to churn flow appeared at a range of $0.127-0.243 \mathrm{~m} / \mathrm{s}$ in both columns.

Churn flow starts when the air flows through the oil column in a form of an open core accompanied by liquid bridges. The diameter of this core changes and in correspondence with the film thickness around this passage. However, one very long bubble might appear in a form of an open column with a very thin and long falling film. This falling film accumulates in the bottom of the column and hold up to create another conduit core with churning regions, Mohammed et al. (2018). Finally, churn flow appears from 0.276 to $0.566 \mathrm{~m} / \mathrm{s}$ gas superficial velocity. The time series data show low values of void fraction that represent the liquid bridges. 


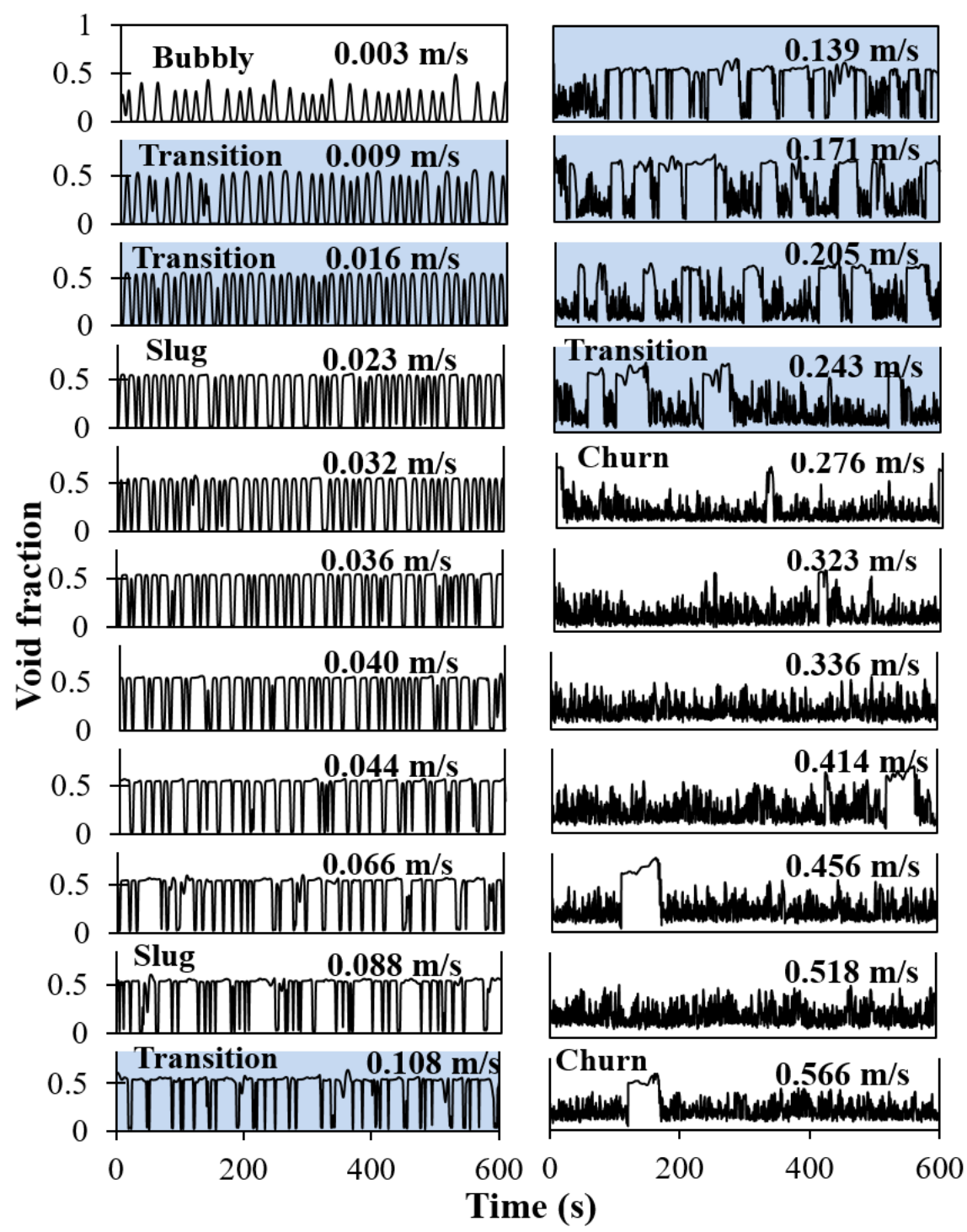

Figure 9: Time series of the cross-sectional averaged void fraction showing the transitions between the flow patterns in 330Pa.s Silicone oil $290 \mathrm{~mm}$ diameter column. The shaded graphs represent the transitions between the flow regimes.

\subsubsection{Mean void fraction}

The time average of the void fraction (here referred to as mean) from the time series data for a wide range of gas flow rates was obtained from ECT measurements. Figure 10 shows the effect of increasing the gas flow rate on the values of the mean void fraction in two different diameter columns. The error bars, in the graph, represent standard errors which were calculated from the standard deviation of the mean void fraction and the square root of the number of samples. SE= $\mathrm{SDMV} / \sqrt{n}$, where ST is standard error, SDMV is standard deviation of the mean void fraction and $\mathrm{n}$ is the number of 
samples. The number of the samples in these experiments was 3; the runs were repeated 3 times for the whole range of the flow rates.

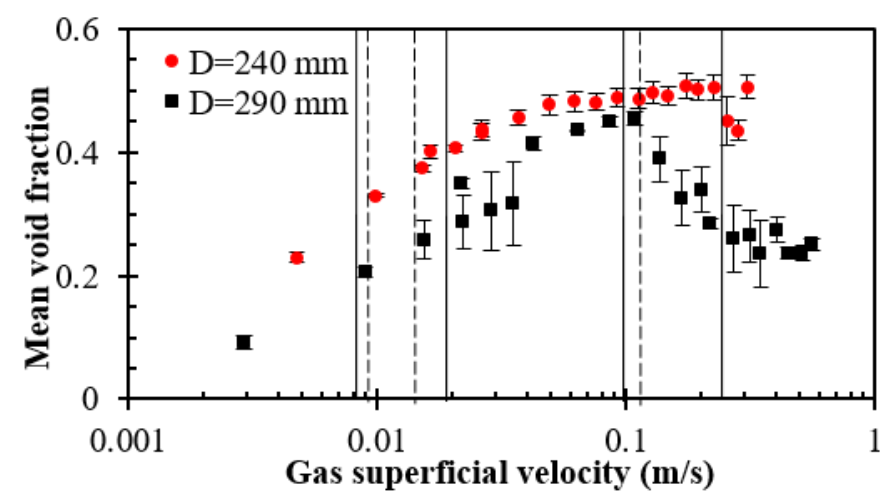

Figure 10: Time-averaged void fraction of air flow with different gas superficial velocities in stagnant high viscosity Silicone oil showing the standard errors for both 240 and $290 \mathrm{~mm}$ diameter columns. The dashed and the sold lines are separating the flow regimes in the 240 and $290 \mathrm{~mm}$ diameter columns respectively.

In general, the figure shows an increase in void fraction with increasing gas superficial velocity as reported by Kuncová and Zahradník (1995). Then there is a sudden drop at higher values of gas superficial velocities. This potentially corresponds to a transition in the flow pattern. The trend in both columns seems to be approximately similar in the bubbly and slug flow regimes. Void fraction increases sharply at lower flow rates (bubbly and beginning of the slug) and slightly in the second half of the slug flow regime. During the transition to churn flow, the values of void fraction showed different trend compared to the previous flow regimes, initially it was observed to increase slightly and then dropped suddenly to rise again in the last flow rate in the $240 \mathrm{~mm}$ diameter column. While in the larger column, it decreased gradually and continued to decrease to the next flow pattern to rise slightly at the end of the churn flow. The standard error showed a reasonable value of $0.2-4 \%$ in the most of the flow rates in the smaller diameter column. However, it seemed to be larger by $0.2-6.8 \%$ in the $290 \mathrm{~mm}$ diameter column. The highest percentage of the error appeared during the transition between the flow regimes where the flow is not structured. The high value of standard error at the start of slug flow is due to the fluctuation of the bubbles size at this stage.

Volume averaged void fraction from the level swell was determined and compared with values obtained from ECT for similar gas superficial velocities. This can be calculated from the initial height of the oil (before air injection) and the final height of air-oil mixture assuming that the volume remains constant inside the column (Hills, 1976). Determining void fraction from level swell was only to show the general trend of changing void fraction and it cannot be conceded as a quantitative measurement due to the uncertainty. Figure 11 illustrates this comparison. The deviation is due to the eruption of the bubbles at the top surface of the liquid. It is quite difficult to select the position of the top surface after the bubble eruption due to the remaining liquid film from the previous erupted bubble. 


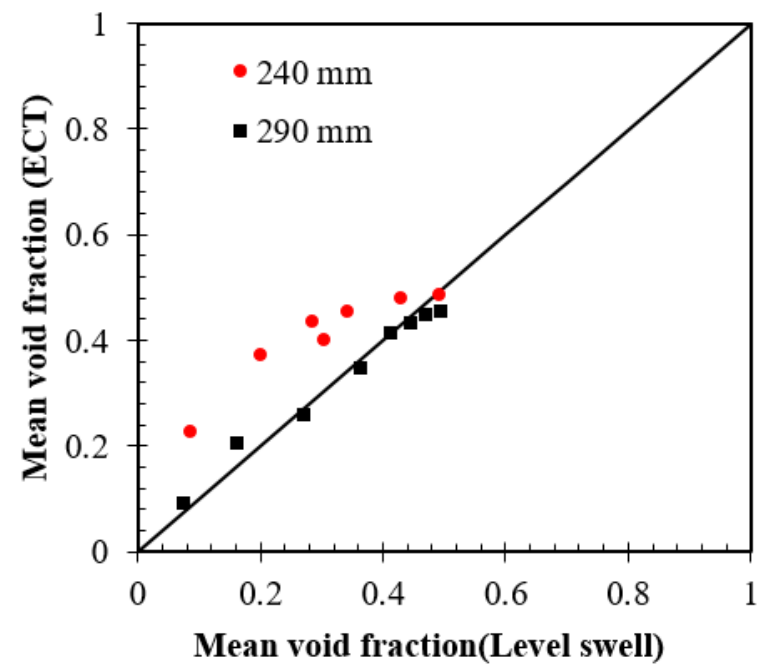

Figure 11: Comparing the time-averaged void fraction from the ECT and the level swell of air flow in a columns of high viscosity oil at different gas superficial velocities.

Mean void fraction was also calculated using the hydrostatic pressure difference in the column using Equation 1;

$\varepsilon_{g}=\frac{\Delta P}{g \times h \times\left(\rho_{g}-\rho_{l}\right)}-\frac{\rho_{l}}{\left(\rho_{g}-\rho_{l}\right)}$

$P$ is pressure, $g$ is gravitational acceleration, $h$ is the distance between both pressure sensors. $\rho_{g}$ and $\rho_{l}$ are gas and liquid densities respectively. Figure 12 compares between mean void fraction measured from the ECT and pressure gradient. The overestimating in the pressure measurements techniques is first due to neglecting of the frictional pressure gradient. Second, large bubbles bursting at the top of the column might cause the pressure to drop to atmospheric pressure and therefore cause large difference in the void fraction estimation.

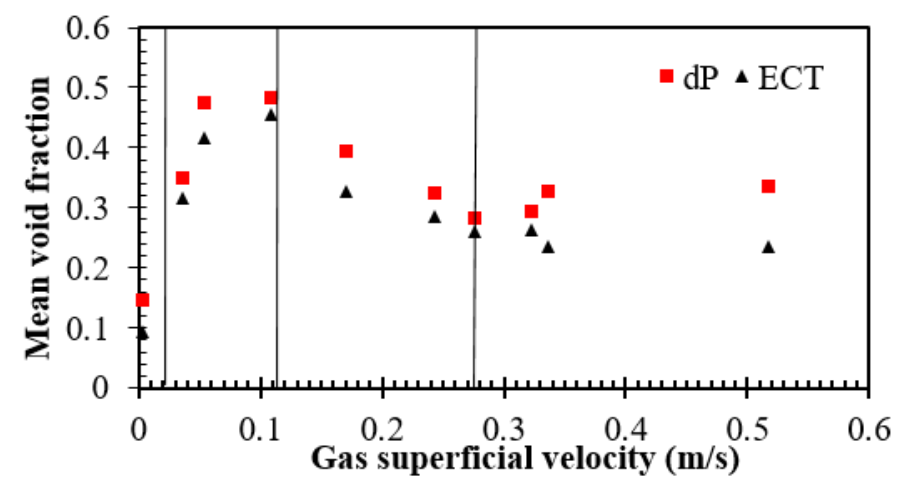

Figure 12: Mean void fraction calculated from ECT and pressure gradient in 330 Pa.s Silicone oil and 290 mm diameter column at different gas superficial velocities. $\mathrm{dP}$ is calculated from Equation 1. 


\subsubsection{Dynamic pressure and pressure gradient}

Pressure profile was monitored for wide range of gas flow rates to study the transitions between the flow patterns in viscous liquids. Two transducers at 2.2 and $3.6 \mathrm{~m}$ from the gas inlet section were employed to measure the pressure in the $290 \mathrm{~mm}$ column. A wide range of gas superficial velocities of $0.003-0.517 \mathrm{~m} / \mathrm{s}$ were used to study the pressure drop inside the column.

Figure 13 illustrates the changing in pressure with time in gas-viscous oil mixture in $290 \mathrm{~mm}$ diameter column for wide range of gas flow rates. At bubbly flow regime $(0.003 \mathrm{~m} / \mathrm{s})$ the pressure drop is approximately constant due to the small size and low frequency of the bubbles. Increasing gas flow rate (bubbly to slug flow) causes fluctuation in the pressure signals. It starts to fluctuate steadily during slug flow at gas superficial velocities of 0.035 and $0.053 \mathrm{~m} / \mathrm{s}$. This is due to the high frequency of the long Taylor bubbles which occupy the cross-section area of the column. On the other hand, this oscillation seems higher and more complicated than the ones in the larger column for the same range of flow rates.

Similar trend of time series of pipe wall pressure was reported by Hasan et al. (2019) for three different axial measuring points in a $240 \mathrm{~mm}$ diameter column. A range of 0.0047 to $0.43 \mathrm{~m} / \mathrm{s}$ gas superficial velocity and Silicon oil of 360 Pa.s were used. Pressure drop values remained approximately constant in the low and middle range of gas flow rates. In the slug flow region $(0.0155$ to $0.1 \mathrm{~m} / \mathrm{s})$ pressure traces showed fluctuations for all measuring points along the pipe due to the effect of Taylor bubbles. Finally, in the high rage of gas flow rates, synchronised oscillations were observed at all measuring points. However, complex structures were reported at the lower location which were attributed to the entrance effect. 

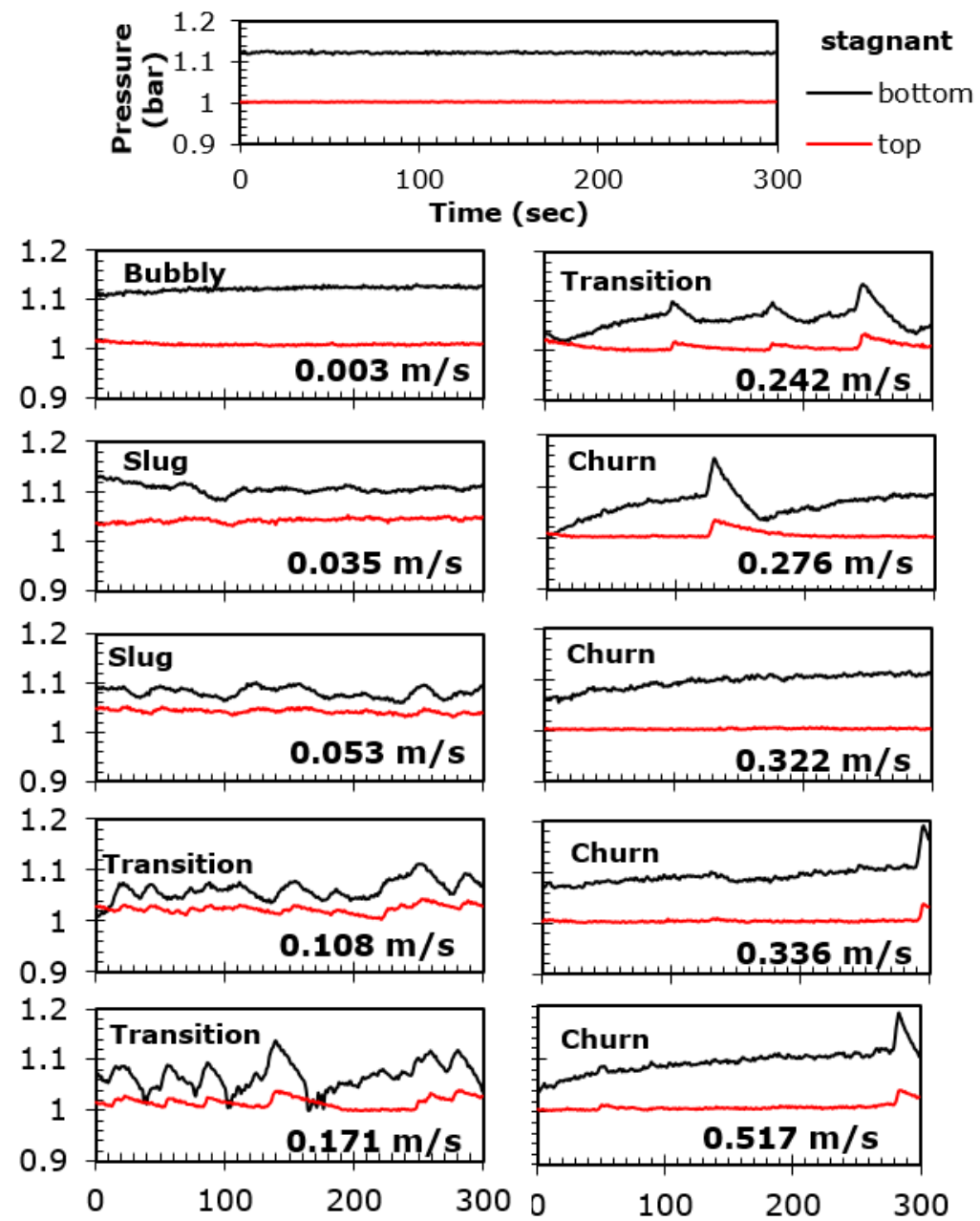

Figure 13: Effect of gas-viscous oil flow on the pressure inside the $290 \mathrm{~mm}$ diameter column for different gas flow rates. The distance between the two sensors is $1.4 \mathrm{~m}$, the bottom sensor is located at $2.2 \mathrm{~m}$ from the gas inlet section.

Mohammed (2017)

Comparison between pressure gradient, which is equal to the pressure difference divided by the distance between the sensors, and void fraction for a wide range of gas flow rates in the column can be found in Figure 14. Increasing gas flow rate increases the void fraction and decreases the pressure gradient, which reaches its minimum at the start of the transition to churn flow $(2.5 \mathrm{KPa} / \mathrm{m})$. Then it starts to increase gradually to the end of the churn flow region where the void fraction seems steady. The pressure head in the column is dominated by the weight of the liquid phase in the gas-liquid mixture. Therefore, in bubbly flow, which consists of bubbles with a low void fraction (thicker liquid film), the pressure gradient is relatively higher, Mohammed (2017)

Increasing the gas flow rate increases the void fraction due to the large Taylor bubbles which almost occupy the pipe cross section area. Increasing the frequency of the bubbles and decreasing the liquid slug length are also considered factors that decrease the pressure gradient. With increasing flow rate where churn starts to appear, pressure gradient starts to 
increase because of: a- increasing the liquid film thickness around the air conduit in the column, and b-increasing the interaction between the two fluids due to increasing the high frequency activity areas (increasing the velocity of the waves and the interaction between both fluids), generating high frictional pressure gradient regions.

The results of the pressure gradient measurements shown in Figure 14 came in agreement in trend in the work done by Owen (1986) who used air-water in a $32 \mathrm{~mm}$ diameter vertical pipe and presented the change of pressure gradient data against dimensionless gas velocity for a number of liquid flows in vertical pipes. According to their results, the pressure gradient values showed a sudden drop at the transition to churn flow due to the high frequency wave activity and friction. A similar increase in the pressure gradient values was observed in this work at the transition to churn flow.

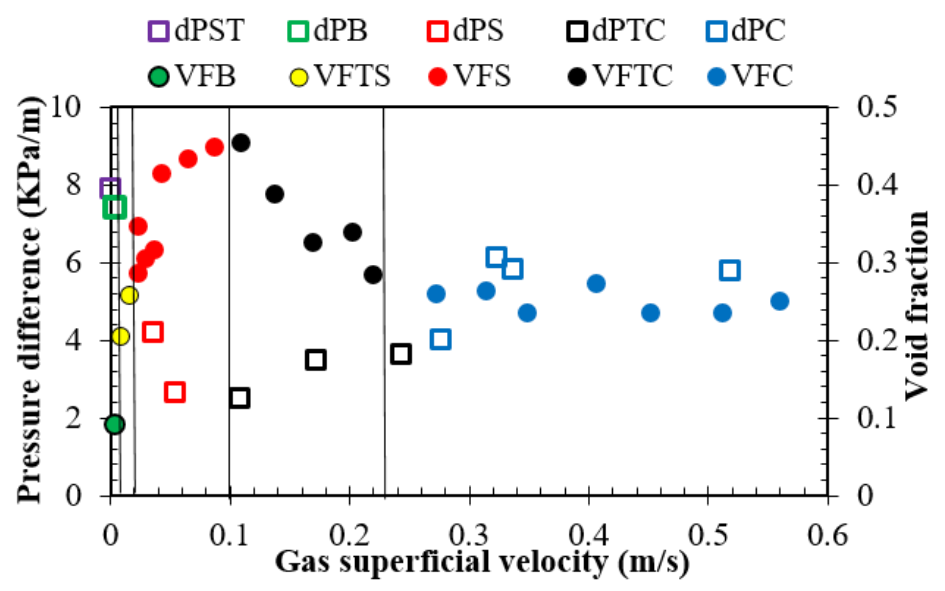

Figure 14: Mean pressure gradient and mean void fraction with changing the flow patterns of gas flow in $330 \mathrm{~Pa}$. Silicone oil and $290 \mathrm{~mm}$ diameter column. $\square \mathrm{dP}$ stagnant, $\square \mathrm{dP}$ in bubbly, $\square \mathrm{dP}$ in slug, $\square \mathrm{dP}$ in churn,,$\square \mathrm{dP}$ in transition to churn, VF; void fraction in $\bullet$ bubbly, transition to slug, $\bullet$ slug, $\bullet$ transition to churn, $\bullet$ churn flow .(Mohammed, 2017)

The behaviour of the pressure gradient with changing the gas flow rate does not agree with the results reported by Pioli et al. (2012). Stagnant glucose syrup of $300 \mathrm{~Pa} . \mathrm{s}$ and $1450 \mathrm{Kg} / \mathrm{m}^{3}$ density was used in $240 \mathrm{~mm}$ column with a maximum gas superficial velocities $0.7 \mathrm{~m} / \mathrm{s}$. They pointed out that in lower gas flow rates the change in pressure decreases rapidly, then at churn flow (the higher gas flow rates), it becomes an "asymptotic trend" of declining, while this work shows a different trend. It shows a sharp drop in the pressure gradient in the bubbly and slug flows and a steady increase during the transition to churn and churn flow. It also reports the minimum pressure gradient at a gas superficial velocity of 0.108 $\mathrm{m} / \mathrm{s}$ which is equal to $2.5 \mathrm{KPa} / \mathrm{m}$, while Pioli et al. (2012) recorded $3 \mathrm{KPa} / \mathrm{m}$ at a gas superficial velocity of $0.7 \mathrm{~m} / \mathrm{s}$. The reason behind the difference in the results might be attributed to the difference in column diameters and the density of the liquids in both experiments. 
Figure 15 shows the time-averaged dynamic pressure change with the gas superficial velocities in the column. The overall picture shows a significant difference in the pressure between the two sensors at low and very high gas flow rates. This difference decreases during the transition to churn flow regime due to the long Taylor bubbles which approximately occupy the whole length of the column. Maximum standard deviation are 0.029 and 0.013 for the bottom and the top positions respectively.

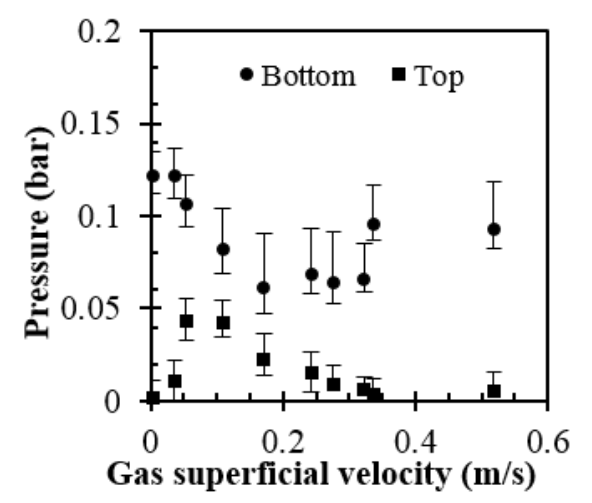

Figure 15: The effect of gas flow rate on the pressure drop inside $290 \mathrm{~mm}$ diameter column and 330 Pa.s Silicone oil using two pressure sensors separated by of $1.4 \mathrm{~m}$.

\subsubsection{Probability density function $(P D F)$ of void fraction}

The PDFs files of viscous liquids for both diameters, obtained in the present work, show trends different from those by Costigan and Whalley (1997). Starting with bubbly flow, $0.003 \mathrm{~m} / \mathrm{s}$ in Figure 16, the PDF appears to have the same characteristics as spherical cap bubbles of water. It features two peaks, one at high void fraction and low probability that corresponds to the spherical Taylor bubble and another with zero void fraction and high probability. At the transition to slug flow, 0.009 to $0.015 \mathrm{~m} / \mathrm{s}$, the PDF of the higher void fraction increases gradually and shifts slightly towards higher void fraction as indication of increasing the frequency and the size of the large bubbles.

Increasing gas superficial velocity to (slug flow) in the viscous oils appear to be more similar to the unstable slug than slug flow in air-water systems. The PDF shows two peaks of void fraction with a considerable gap between the lower peak and the higher peak for the whole range of slug flow $(0.023$ to $0.088 \mathrm{~m} / \mathrm{s})$. The lower peaks feature low values and the higher peaks are at higher values of void fraction. Slug flow in both columns features higher PDF value for the Taylor bubbles. The value of PDF decreases with increasing the gas superficial velocity at the transition to churn flow. This indicates the decrease of the length of Taylor bubbles due to the creation of the liquid bridges $(0.108-0.243 \mathrm{~m} / \mathrm{s})$.

Further increase in gas flowrate to $0.566 \mathrm{~m} / \mathrm{s}$ the higher void fraction peak decreased dramatically to become smaller than the lower void fraction peak. This is churn flow regime, which consists of large areas of aerated liquid bridges. The time 
series of void fraction shown earlier in Figure 9 depict the dynamic void fraction behaviour corresponding to this flow pattern.

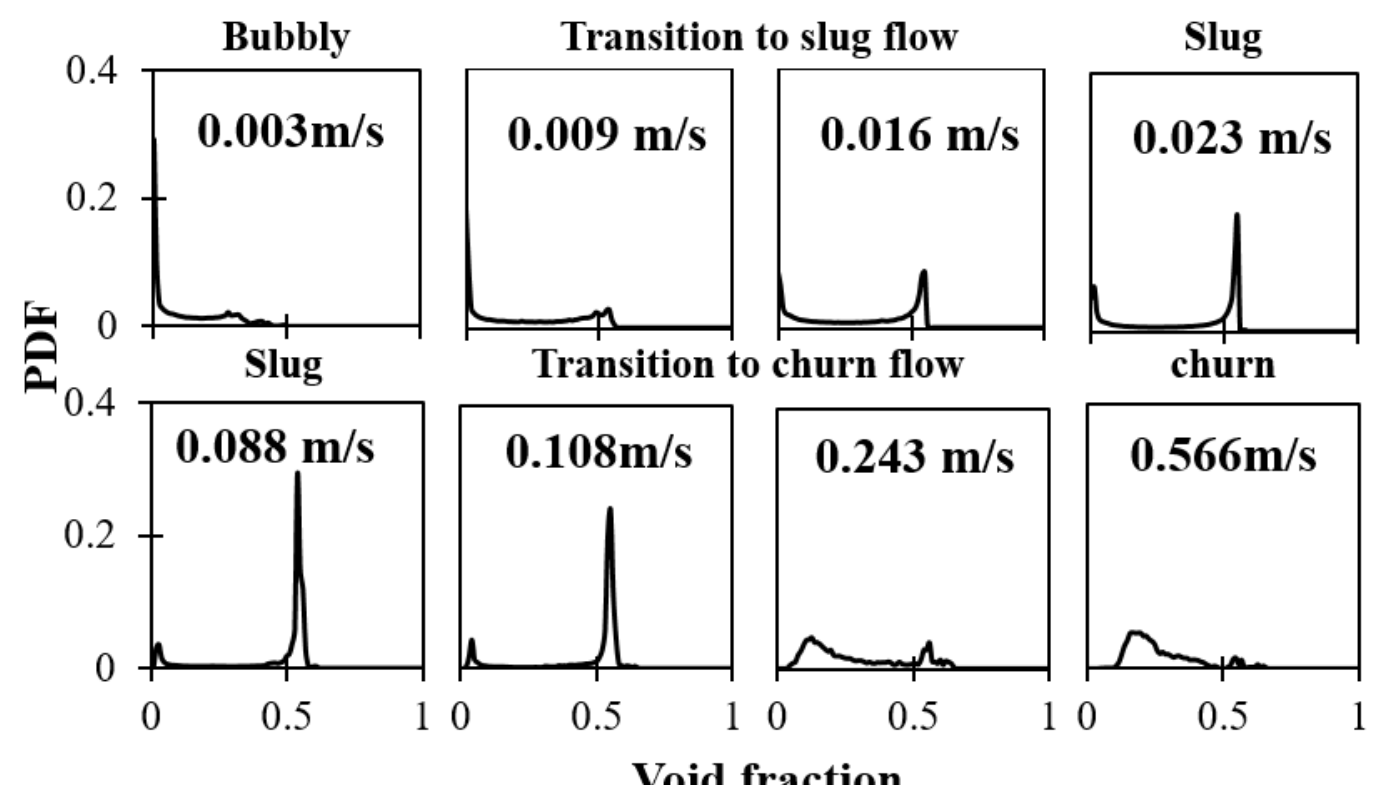

Figure 16: Probability density function profile showing three different flow regimes and their transitions.

\subsection{Structure of the Flow in Viscous Oils}

\subsubsection{Motion of the bubbles and liquid slugs}

Structure velocities can be determined from cross-correlation of the void fraction measured by the two planes of the ECT. The time delay between both signals and the distance between both planes are used to calculate a structure velocity. This is the distance between the planes, divided by the time lag of the signals, calculated by means of auto-correlation.

Figure 17 shows the structure velocity calculated for both columns for the range of gas superficial velocities studied. The average data for the structure velocity in Figure 17 shows a linear trend for both columns at low gas flow rates. However, as the gas flow rate increases the rate of increase of structure velocity decreases, as the profile plateaus. It is higher in bubbly and slug flow regimes while it decreases in the transition to churn and churn flow due to the characteristics of the flow in these patterns. In bubbly and slug flow, where the Taylor bubble is dominating the flow structure, larger bubbles rise faster because of the balance between the buoyant weight and the drag force (Dumitrescu (1943) Gibson (1913)). Then, with the higher gas flow rates, the increasing rate of the structure velocity decreases dramatically, due to the coalescence of the bubbles and the growth in the lengths of the bubbles. Moreover, with changing the flow regime, the structure velocity indicates a completely different behaviour. It loses its trend and becomes almost random in churn flow 
at the higher gas flow rates. The error bars values range between $0.03-9 \%$ and $0.07-16.8 \%$ in the 240 and $290 \mathrm{~mm}$ diameter columns respectively. The maximum values of the error occur marking transition between flow regimes.

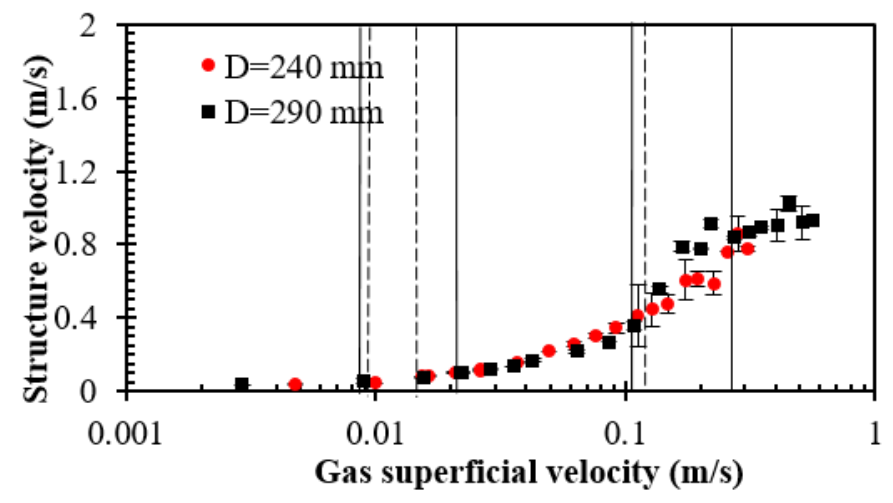

Figure 17: Structure velocity with standard errors comparing 240 and $290 \mathrm{~mm}$ diameter columns and high viscosity Silicone oil. The dashed and the sold lines are separating the flow regimes in the 240 and $290 \mathrm{~mm}$ diameter columns respectively

A comparison between experimental and numerical structure velocity is shown in Figure 18 . The bubble velocity, $U_{T B}$ is calculated using equation by Viana et al (2003); $U_{T B}=C_{o}\left(U_{g s}+U_{l s}\right)+K F_{r} \sqrt{g D_{B}} \cdot U_{g s}$ and $U_{l s}$ are the gas and liquid superficial velocities respectively. $C_{o}$ represents the ratio of the maximum centreline velocity of the bubble to the mean upward liquid velocity. It is calculated using equation proposed by Dukler and Fabre (1994) and Guet et al. (2004). $K=$ $\frac{0.905}{\left(1-\varepsilon_{g s}\right)^{3.95}}, F_{r}$ is Froude number, and $D_{B}$ is bubble diameter. The maximum relative error between the experimental and empirical structure velocities in both columns show values of 0.5 and 2.2 in 240 and 290 mm diameter columns respectively. Relative Error, $R E_{\text {accuracy }}$ was calculated from $R E_{\text {accuracy }}=\frac{E C T-\text { empirical }}{E C T}$. The experimental values seem to scatter (decrease) during the transition to churn flow in the smaller column and in both transition to churn and churn flow in the larger diameter column. This is illustrated in Figure 18. The deviation between both values at high gas flowrates is because the equation is based on bubble buoyancy, which can only be applicable for bubbly, and slug flow.

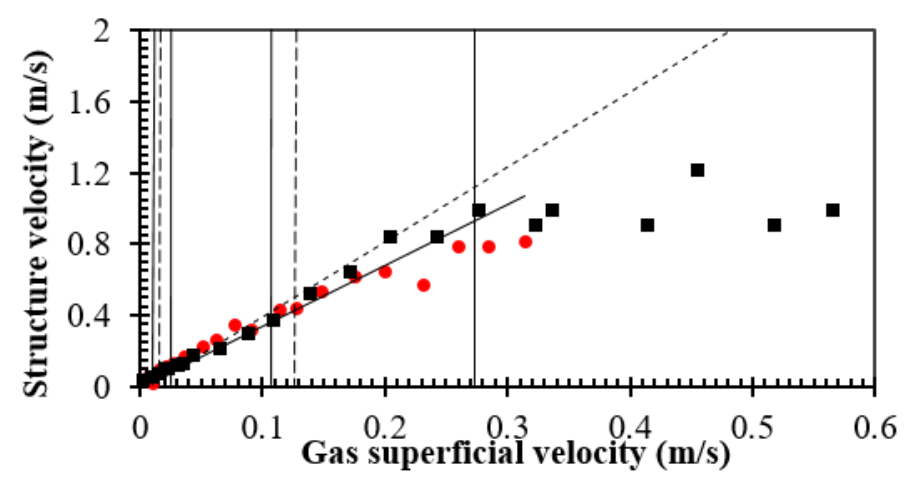

Figure 18: Theoretical and experimental structure velocities in viscous Silicone oil for both columns. •:240mm, 
290mm (experimental) and - 240mm, ---290mm (from Viana et al. (2003) and Guet et al. (2004)). The dashed and the sold lines are separating the flow regimes in the 240 and $290 \mathrm{~mm}$ diameter columns respectively.

\subsubsection{The characteristics of large bubbles and liquid slugs}

The lengths of large bubbles and of liquid slugs in viscous Silicone oil were determined for a wide range of gas flow rates. The lengths were calculated from the time each bubble/liquid slug take to pass through the ECT probes at a fixed gas velocity. The length of the bubbles represents the large bubbles/Taylor bubbles at bubbly and slug flow and the gas slugs between the liquid bridges at churn flow.

Figure 19 presents the lengths of the large bubble and liquid slug in both columns. It is clear that in both columns, the length of the large bubble increases with increasing gas flow rate. It increases gradually at lower gas flow rates due to the structure of slug flow to reach the maximum $9.5 \mathrm{~m}$ at the start of the transition to churn flow. This very high value of bubble lengths represent the open core with the falling film which have been explained earlier. Then it starts to fluctuate for the rest of the transition in the smaller column. Similar behaviour is seen in the larger column. The bubble length increases to $13.9 \mathrm{~m}$ at a gas superficial velocity $0.219 \mathrm{~m} / \mathrm{s}$. This takes place at the beginning of the transition to churn flow regime. Then it starts to fluctuate as it does in the smaller column, but it drops suddenly at the end of the churn flow regime to reach approximately $3.0 \mathrm{~m}$. A detailed explanation with schematic drawing showing the very long bubbles which appear as an open core are presented in Mohammed et al. (2018). To understand the results in these two graphs, it might be worth comparing each flow rate with the corresponding time series of void fraction in Figure 8 and Figure 9.

The liquid slug length shows a different aspect with a changing column diameter. It remains shorter than the length of the slug in the smaller column for the entire range of flow rates, while it becomes longer than the bubbles in the $290 \mathrm{~mm}$ column in the transition to churn and churn flow regimes. This is due to the characteristic of churn flow where no defined Taylor bubble can be found. The error bars in Figure 19 represent the standard error which show a low value in the low gas flow rates in both columns; then they increase in values in higher gas flow rates where the structure of the flow is not homogenous. The high values of the standard errors in both columns appear in very high gas flow rates due to the unstable structure at these flow regimes (irregular/non uniform slugs with varying lengths) 


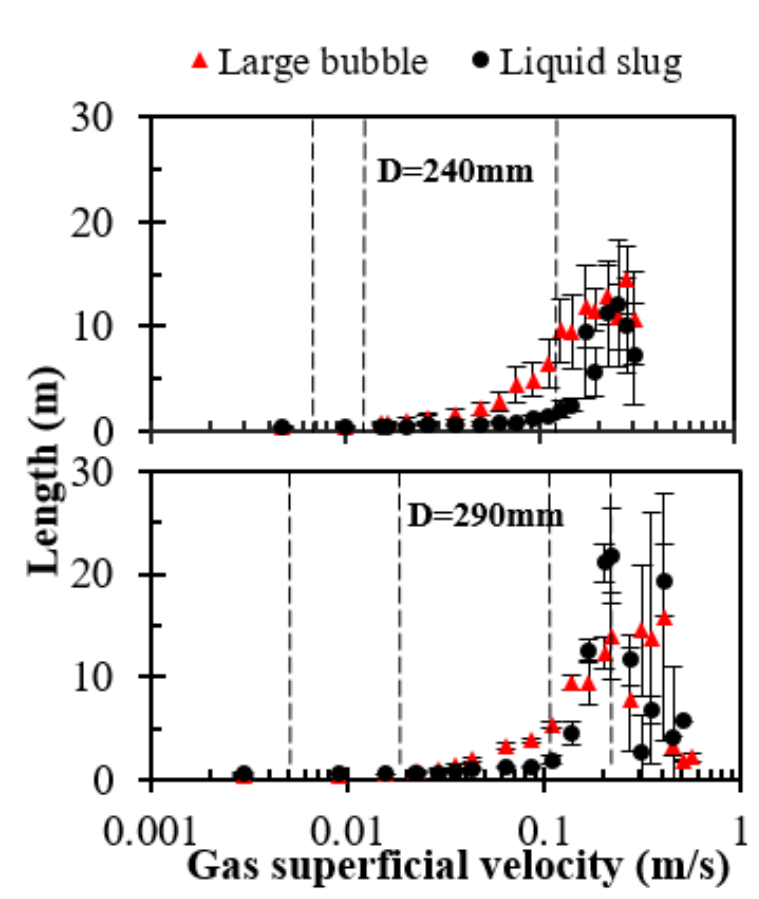

Figure 19: Comparing the standard error for the mean lengths of Taylor bubble and liquid slug for both 240 and $290 \mathrm{~mm}$ diameter columns. The dashed lines are separating the flow regimes.

The frequency of the large bubbles was calculated from the time series data by counting the number of the bubbles per unit time for each gas flow rate. The frequency of the large bubbles appears to be affected by the increase in the gas flow rate as shown in Figure 20. It shows a different trend in each flow regime. In both columns, the frequency of the large bubbles increases steadily with an increasing gas flow rate during the bubbly flow regime. Then it declines gradually as the regime transitions to slug flow due to the increased coalescence of bubbles forming Taylor bubbles. The minimum values of the frequency obtained at the beginning of the transition to churn flow regime are 0.029 and $0.023 \mathrm{~Hz}$ in 240 and $290 \mathrm{~mm}$ diameter columns respectively, as the bubbles are very long at this stage. The frequency starts to increase with a decrease in the length of the large bubbles by the end of the churn flow. This is due to the rise in the number of liquid bridges breaking the long bubbles. The results from both diameters show that the frequency of the large bubbles is dependent on the gas flow rate. However, according to Azzopardi et al. (2014), the frequency is not affected significantly by the gas flow rate. The standard errors showed value of $0.04 \%$ to $5.7 \%$ in the larger diameter column, while it recorded 0.089-3.9\% in the $240 \mathrm{~mm}$ diameter column. See Figure 20. 


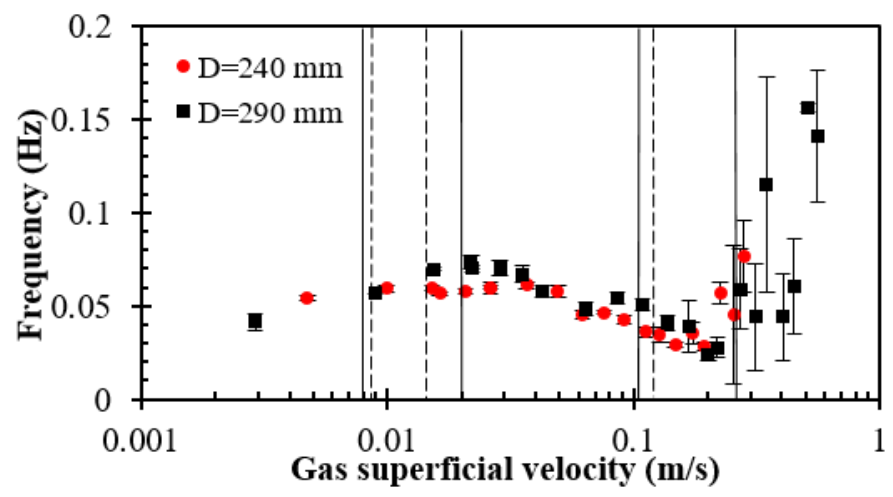

Figure 20: Frequency of large bubbles in a high viscosity oil and two different diameter columns. Error bars are the standard errors of the frequency. The dashed and the sold lines are separating the flow regimes in the 240 and $290 \mathrm{~mm}$ diameter columns respectively.

The bubble frequency can be presented in terms of Strouhal number $\left(S t=\frac{f \cdot D}{v}\right)$. It takes into consideration the column diameter, $D$ structure velocities, $v$ and bubble frequency, $f$. In Figure 21, this is plotted against Froude number $(F r=$ $\left.\frac{U_{s g}}{\sqrt{g . D}}\right), U_{s g}$ is gas superficial velocity and $g$ is gravitational acceleration. An inverse relationship occurs in most flow patterns. However, expectedly, frequency seems to increase at high Froude numbers. Figure 20 is presented in order to try and establish if a correlation for the prediction of bubble frequency can be obtained and also constitutes an attempt to observe any changes of pattern with the onset of transition of flow regimes. However, no firm conclusions about correlations or patterns can be drawn from the frequency data.

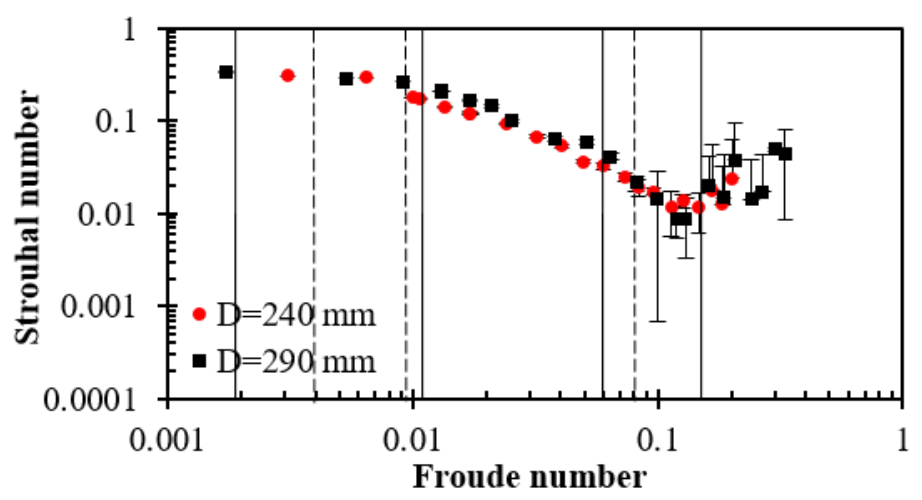

Figure 21: Effect of the gas superficial velocity on the Strouhal number in two different diameter columns.

Another parameter that can be used to identify the structure of the flow in the column is the liquid film. The liquid film behaves as a falling film enveloping the gas pockets in the bubbly and slug flow regimes. The characteristics of this liquid film change totally in the transition to churn and churn flow regimes. The film becomes thicker and seems to travel in different directions due to the process of flooding. The film thickness around the large bubbles was calculated from the mean void fraction of the gas-oil in the column. It is determined using the geometric relationship $\delta=(\mathrm{D} / 2)\left(1-\sqrt{\varepsilon_{g}}\right)$. Where 
$\delta$ is the film thickness, D is pipe diameter and $\varepsilon_{g}$ is void fraction obtained from the ECT. Figure 22 illustrates how mean film thickness depends on gas superficial velocity. As can be seen, the values of the film thickness are more affected by increasing the gas flow rate. It decreases gradually by $32 \mathrm{~mm}$ in the bubbly and slug flow due to the increasing size of the large bubbles, which occupy the column's cross-section. Then increases slightly in the middle of the transition to churn regime to reach its maximum of $75 \mathrm{~mm}$ in the middle of the churn flow due to the derange of the liquid film. The maximum values of the standard error in both columns is; $0.2 \%$ and $1.1 \%$ for the 240 and $290 \mathrm{~mm}$ diameters respectively.

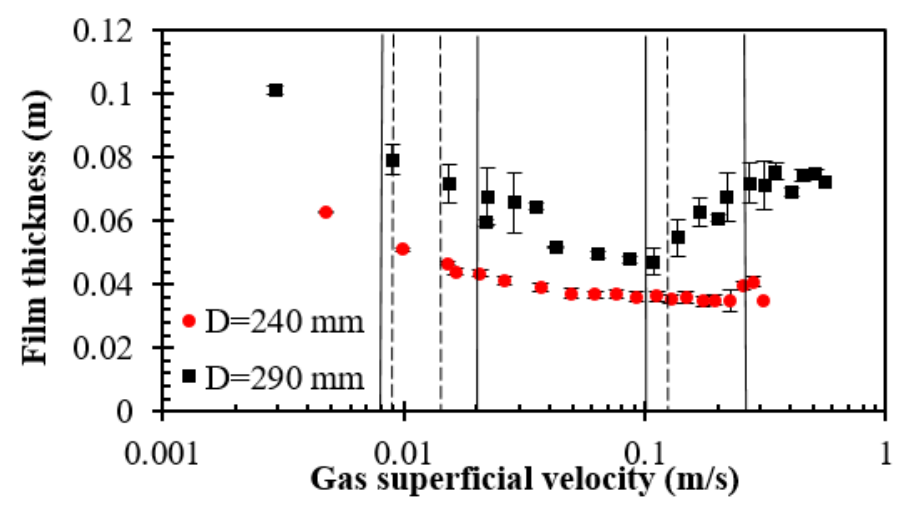

Figure 22: Film thickness around the large bubbles created in viscous oil in two different column diameters and a wide range of flow rates. Dashed and sold lines are separating the flow regimes in the 240 and 290 mm diameter columns respectively.

\subsection{Effect of temperature}

Since all the experiments in the present study were conducted in a laboratory environment at room temperature, fluctuations in temperature are projected to have a substantial impact on the viscosity and therefore hydrodynamic characteristics of the flow, considering the substantial friction in the test section due to high viscosity. This section reports a sensitivity study to the two-phase flow hydrodynamic attributes to temperature in 360 Pa.s Silicone oil in the $240 \mathrm{~mm}$ diameter column. Oil temperatures of $20,22,23$, and $30{ }^{\circ} \mathrm{C}$, which are corresponding to $360,340,337$, and $302 \mathrm{~Pa} . \mathrm{s}$ viscosity respectively, were used with gas superficial velocities of $0.005-0.3 \mathrm{~m} / \mathrm{s}$. The thermocouple, which was employed to measure the temperature, was located $1 \mathrm{~m}$ above the gas injection points at the bottom of the column. A viscositytemperature test was carried out by using a Brookfield Viscometer (DV-II+Pro) and samples of the Silicone oils with different temperatures to determine the viscosity of the oil used in both columns in different temperatures. This Viscometer measures the oil viscosity at certain a constant shear rate (Viscosity is a measure of the resistance of the fluid to flow). 
Figure 23 illustrates the effect of changing temperature on mean void fraction, structure velocity, large bubble length, and film thickness in a $240 \mathrm{~mm}$ diameter column. Mean void fraction seems to be independent of the temperature. However, for the viscosity (360 Pa.s), the mean void fraction value appears to be at a minimum compared to the other viscosities. Structure velocity shows a different trend compared to the mean void fraction. The values of structure velocity seem almost constant with changing temperature, while they become more scattered with increasing the gas superficial velocities above $0.07 \mathrm{~m} / \mathrm{s}$. Taylor bubbles' length exhibits a similar behaviour by changing the temperature. They appear more affected by temperature rise at high gas flow rates. This behaviour might be attributed to the unstable structure of the flow at high gas flow rates besides the effect of temperature on the viscosity. Unlike Taylor bubble lengths, the film thickness seems almost constant with changing temperature except for the values recorded at $20^{\circ} \mathrm{C}$.
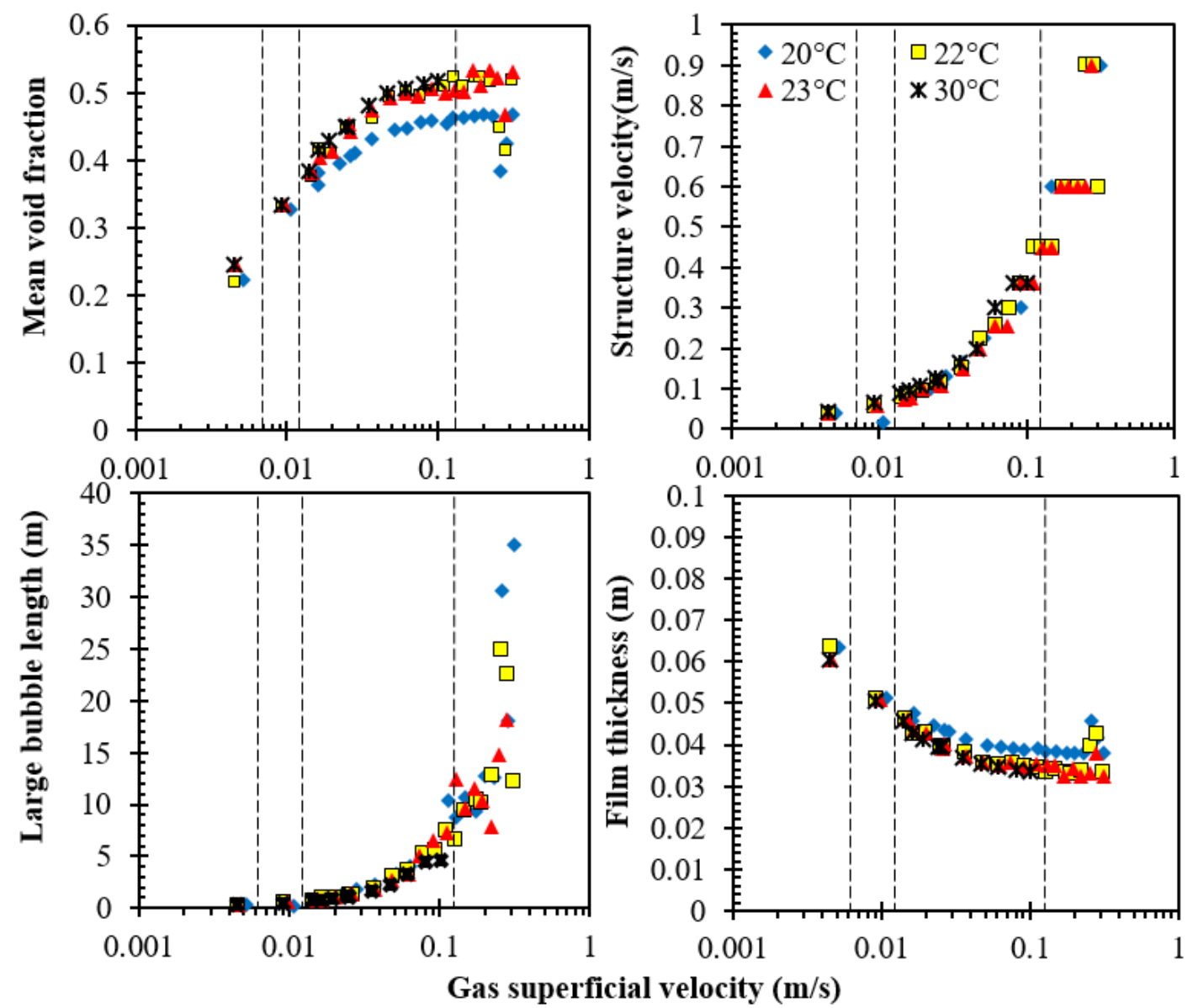

Figure 23: Effect of temperature on the mean void fraction, structure velocity, large bubble length, and film thickness in $240 \mathrm{~mm}$ diameter column at different flow regimes. Dashed lines are separating the flow regimes in the columns. 


\section{Conclusions}

The hydrodynamics Transition between flow regimes in very viscous liquids has been investigated over a wide range of gas flow rates. Characteristics of gas flow in stagnant Silicon oils of 360 and 330 Pa.s were studied in columns of 240 and $290 \mathrm{~mm}$ diameters respectively. ECT and Pressure transmitters were employed to collect information about the characteristics of two-phase flow in the columns. In general, the experimental results for gas flow in high viscosities Silicone oils show a significant difference compared to water and low viscosity liquids in literature. Three flow regimes with two transitions of quite different structures have been characterised in the range of gas flow rates that have been used.

- Two main types of bubbles were observed in high viscosity oils; large bubbles; approximately equal to pipe diameter (spherical, ellipsoidal and Taylor bubble) and small (spherical and ellipsoidal) of millimetrescentimetre.

- Transition to slug flow starts with bubbles coalescence due to the creation of large bubbles of different sizes and shapes, spherical and ellipsoidal.

- Transition to slug flow occurs at gas superficial velocities of $0.011 \mathrm{~m} / \mathrm{s}$ in the $240 \mathrm{~mm}$ diameter column. While it appears between 0.009 to $0.016 \mathrm{~m} / \mathrm{s}$ in the $290 \mathrm{~mm}$ diameter column.

- In slug flow, Taylor bubbles appear as a long bubble with a diameter equal approximately to the pipe diameter with rounded top and end.

- No turbulent circulation is appeared at the wake of the large bubbles, unlike low viscosity liquids.

- Transition to churn flow starts when the very long Taylor bubbles start to brake by flooding of the falling film around the bubble as a liquid bridge. Frequency and liquid bridges increase to create a random shape conduit with a complex structure.

- Transition to churn flow appears in the range of $0.127-0.314 \mathrm{~m} / \mathrm{s}$ and $0.108-0.243 \mathrm{~m} / \mathrm{s}$ in the 240 and $290 \mathrm{~mm}$ diameter column respectively.

- Transition to slug flow regime occurs in a wider range of gas flow rates in the larger diameter column due to the pipe wall effect, while transition to churn flow is longer in the smaller diameter column.

- Mean Void fraction increases gradually from bubbly to the end of slug flow in both columns due to increasing the size of the bubbles. Then it decreases gradually at the transition to churn and churn flow in the $290 \mathrm{~mm}$ diameter column. While it shows a slight fluctuation at the transition to churn flow regime in the smaller diameter column. 
- Structure velocity seems to increase at a constant rate with increasing the bubbles size (increasing gas flow rate) from bubbly to slug flow in both column. While at the transition to churn flow, the rate of increasing of the structure velocity seemed to decrease.

- Large bubbles length increases gradually with increasing gas flow rate at the transition to slug flow in both columns. However, it shows a fluctuation in values at the transition to churn flow due to the unstable structure of this flow pattern in both columns.

- Large bubbles frequency seen to increase steadily with increasing gas flow rate at the transition to slug flow in both columns. While it appears to fluctuate at the transition to churn flow as a result of increasing the liquid bridges which break the very long bubble.

- Liquid viscosity decreases with increasing temperature. Mean void fraction and film thickness seem to be independent on temperature. Structure velocity and Taylor bubbles lengths appear more effected by changing temperature at high gas flow rates (transition to churn flow).

\section{Dedication}

This work is dedicated to the memory of Professor Barry J Azzopardi a supervisor, colleague and good friend who passed away. The new findings reported in this study could not have been achieved without his knowledge, guidance and support.

\section{Acknowledgements}

This work is granted by the Kurdistan Regional Government in Iraq and the MEMPHIS EPSRC (EP/K003976/1) programme.

\section{References}

ABDULKAREEM, L. A. 2011. Tomographic investigation of gas-oil flow in inclined risers. University of Nottingham. AZZOPARDI, B., ABDUlKAREEM, L., ZHAO, D., THIELE, S., DA SILVA, M., BEYER, M. \& HUNT, A. 2010. Comparison between electrical capacitance tomography and wire mesh sensor output for air/silicone oil flow in a vertical pipe. Industrial \& Engineering Chemistry Research, 49, 8805-8811.

AZZOPARDI, B. J. 2006. Gas-liquid flows, New York, Begell House.

AZZOPARDI, B. J., PIOLI, L. \& ABDULKAREEM, L. A. 2014. The properties of large bubbles rising in very viscous liquids in vertical columns. International Journal of Multiphase Flow, 67, 160-173.

BIRD, J. C., DE RUITER, R., COURBIN, L. \& STONE, H. A. 2010. Daughter bubble cascades produced by folding of ruptured thin films. Nature, 465, 759-762.

BOUSMAN, W., MCQUILLEN, J. \& WITTE, L. 1996. Gas-liquid flow patterns in microgravity: effects of tube diameter, liquid viscosity and surface tension. International Journal of Multiphase Flow, 22, 1035-1053.

BRAUNER, N. \& BARNEA, D. 1986. Slug/Churn transition in upward gas-liquid flow. Chemical Engineering Science, 41, 159-163.

BRENNEN, C. E. \& BRENNEN, C. E. 2005. Fundamentals of multiphase flow, Cambridge university press.

CHEN, X. T. \& BRILL, J. P. 1997. Slug to churn transition in upward vertical two-phase flow. Chemical Engineering Science, 52, 4269-4272.

COSTIGAN, G. \& WHALLEY, P. 1997. Slug flow regime identification from dynamic void fraction measurements in vertical air-water flows. International Journal of Multiphase Flow, 23, 263-282.

CROWE, C. T. 2005. Multiphase flow handbook, CRC press. 
DUKLER, A. \& FABRE, J. 1994. Gas-liquid slug flow. Multiphase science and technology, 8, 1-4.

DUMITRESCU, D. T. 1943. Strömung an einer Luftblase im senkrechten Rohr. ZAMM-Journal of Applied Mathematics and Mechanics/Zeitschrift für Angewandte Mathematik und Mechanik, 23, 139-149.

FENG, J. Q. 2008. Buoyancy-driven motion of a gas bubble through viscous liquid in a round tube. Journal of Fluid Mechanics, 609, 377-410.

GIBSON, A. 1913. On the motion of long air-bubbles in a vertical tube. The London, Edinburgh, and Dublin Philosophical Magazine and Journal of Science, 26, 952-965.

GUET, S., OOMS, G., OLIEMANS, R. \& MUDDE, R. 2004. Bubble size effect on low liquid input drift-flux parameters. Chemical engineering science, 59, 3315-3329.

HASAN, A. H., MOHAMMED, S. K., PIOLI, L., HEWAKANDAMBY, B. N. \& AZZOPARDI, B. J. 2019. Gas rising through a large diameter column of very viscous liquid: Flow patterns and their dynamic characteristics. International Journal of Multiphase Flow, 116, 1-14.

HEWITT, G. F. \& HALL-TAYLOR, N. 1970. Annular two-phase flow, Pergamon.

HILLS, J. 1976. The operation of a bubble column at high throughputs: I. Gas holdup measurements. The Chemical Engineering Journal, 12, 89-99.

HINZE, J. 1955. Fundamentals of the hydrodynamic mechanism of splitting in dispersion processes. AIChE Journal, 1, 289-295.

KAJERO, O. T., ABDULKADIR, M., ABDULKAREEM, L. \& AZZOPARDI, B. J. 2018. Experimental study of viscous effects on flow pattern and bubble behavior in small diameter bubble column. Physics of Fluids, 30, 093101.

KUNCOVÁ, G. \& ZAHRADNÍK, J. 1995. Gas holdup and bubble frequency in a bubble column reactor containing viscous saccharose solutions. Chemical Engineering and Processing: Process Intensification, 34, 25-34.

LLEWELLIN, E., DEL BELLO, E., TADDEUCCI, J., SCARLATO, P. \& LANE, S. 2012. The thickness of the falling film of liquid around a Taylor bubble. Proceedings of the Royal Society A: Mathematical, Physical and Engineering Science, 468, 1041-1064.

MARASHDEH, Q. 2009. Validation of Electrical Capacitance Volume Tomography with Applications to Multi-phase Flow System [Masters of Science]. The Ohio State University, Columbus, OH.

MISHIMA, K. \& ISHII, M. 1984. Flow regime transition criteria for upward two-phase flow in vertical tubes. International Journal of Heat and Mass Transfer, 27, 723-737.

MOHAMMED, S. K. 2017. Gas-high viscosity oil flow in vertical large diameter pipes. $\mathrm{PhD}$, University of Nottingham.

MOHAMMED, S. K., HASAN, A., DIMITRAKIS, G. \& AZZOPARDI, B. J. 2018. Churn flow in high viscosity oils and large diameter columns. International Journal of Multiphase Flow, 100, 16-29.

NICKLIN, D., WILKES, J. \& DAVIDSON, J. 1962. Two-phase flow in vertical tubes. Trans. Inst. Chem. Eng, 40, 6168.

OTAKE, T., TONE, S., NAKAO, K. \& MITSUHASHI, Y. 1977. Coalescence and breakup of bubbles in liquids. Chemical Engineering Science, 32, 377-383.

OWEN, D. G. 1986. An experimental and theoretical analysis of equilibrium annular flows. University of Birmingham.

PANDIT, A., PHILIP, J., DAVIDSON, J. \& DODD, P. The generation of small bubbles in liquids. International Chemical Reaction Engineering Conference, 1987. 72-82.

PHILIP, J., PROCTOR, J., NIRANJAN, K. \& DAVIDSON, J. 1990. Gas hold-up and liquid circulation in internal loop reactors containing highly viscous Newtonian and non-Newtonian liquids. chemical Engineering science, 45, 651-664.

PIOLI, L., BONADONNA, C., AZZOPARDI, B., PHILlIPS, J. \& RIPEPE 2012. Experimental constraints on the outgassing dynamics of basaltic magmas. Journal of Geophysical Research: Solid Earth, 117.

PRADEEP, C., YAN, R., VESTØL, S., MELAAEN, M. C. \& MYLVAGANAM, S. 2014. Electrical capacitance tomography (ECT) and gamma radiation meter for comparison with and validation and tuning of computational fluid dynamics (CFD) modeling of multiphase flow. Measurement Science and Technology, 25, 075404.

RADOVCICH, N. A. \& MOISSIS, R. 1962. The transition from two phase bubble flow to slug flow. Cambridge, Mass.: MIT Division of Sponsored Research,[1962].

ROCHA, L., MIRANDA, J. \& CAMPOS, J. 2017. Wide range simulation study of taylor bubbles in circular milli and microchannels. Micromachines, 8, 154.

RUZICKA, M. C., DRAHOŠ, J., MENA, P. C. \& TEIXEIRA, J. A. 2003. Effect of viscosity on homogeneousheterogeneous flow regime transition in bubble columns. Chemical Engineering Journal, 96, 15-22.

SHARAF, D., PREMLATA, A., TRIPATHI, M. K., KARRI, B. \& SAHU, K. C. 2017. Shapes and paths of an air bubble rising in quiescent liquids. Physics of Fluids, 29, 122104.

SHEN, X., SCHLEGEL, J. P., CHEN, S., RASSAME, S., GRIFFITHS, M. J., HIBIKI, T. \& ISHII, M. 2014. Flow Characteristics and Void Fraction Prediction in Large Diameter Pipes. Frontiers and Progress in Multiphase Flow I. Springer.

SHU, W. 1984. A viscosity correlation for mixtures of heavy oil, bitumen, and petroleum fractions. Society of Petroleum Engineers Journal, 24, 277-282. 
TAITEL, Y., BORNEA, D. \& DUKLER, A. E. 1980. Modelling flow pattern transitions for steady upward gas-liquid flow in vertical tubes. AICHE. J., 26, 345-354.

VIANA, F., PARDO, R., YANEZ, R., TRALLERO, J. L. \& JOSEPH, D. D. 2003. Universal correlation for the rise velocity of long gas bubbles in round pipes. Journal of Fluid Mechanics, 494, 379-398.

WILKINSON, P. M., VAN SCHAYK, A., SPRONKEN, J. P. M. \& VAN DIERENDONCK, L. 1993. The influence of gas density and liquid properties on bubble breakup. Chemical Engineering Science, 48, 1213-1226.

WRAITH, A. 1971. Two stage bubble growth at a submerged plate orifice. Chemical Engineering Science, 26, 16591671. 